Erik Strauss Sena Dominguito de Oliveira

\title{
Desenvolvimento de um cubo de roda traseiro para veículo mini-Baja utilizando técnicas de otimização topológica
}

Projeto de Graduação

Projeto de Graduação apresentado ao Departamento de Engenharia Mecânica da PUC-Rio.

Orientador : Ivan Fábio Mota de Menezes

Coorientador: Matheus Hoffmann Brito 


\section{Agradecimentos}

Primeiramente gostaria de agradecer incondicionalmente aos meus pais, Sergio e Denise, que proveram amor, saúde e educação ao longo de toda minha vida, sempre me botando a frente de seus interesses. Ao meu irmão Igor, por estar presente nos momentos difíceis. Sei que não sou fácil, mas espero corresponder os esforços que vocês fizeram por mim ao longo de todos esses anos e que se orgulhem do homem que me tornei.

A minhas avós Marlene e Heloísa e minha querida dinda Ivana, que sempre apoiaram e incentivaram desejando sucesso e prosperidade em qualquer decisão que eu tomasse. Ao meu avô Átila em especial, cujo maior desejo em vida era a plena educação e bem estar de seus netos, sei que está orgulhoso de mim e de nossa conquista.

Ao meu professor orientador Ivan, que no atual cenário pândemico, aturou minha mudança de tema e nunca hesitou em prover suporte as minhas necessidades e questionamentos. Ao Matheus, coorientador, amigo e companheiro de Baja, pela paciência e ensinamentos nos últimos 4 anos e na execução deste trabalho.

Um agradecimento especial a Equipe Reptiles, onde num intervalo de 2 anos vivi a maior e melhor montanha-russa de emoções na minha vida. Um obrigado a todos os companheiros que de alguma forma influenciaram em quem eu sou: Milhouse, Richard, Cunha, Luciana, Vivian, Henrique, Lelê, Montesanto, Zé, Caipira, Juliana, Nicos, Gabriel, Jessica, Luisa, Wang, Sid, Gi, Caroline, Marina e todos os outros os membros e ex-membros que contribuiram para o crescimento e manutenção deste projeto maravilhoso. Um obrigado aos professores Parise e José Paulo que através do projeto, permitem jovens sonharem a se tornar engenheiros melhores.

Aos meus amigos de vida, Bruno, Pedro, Nicholas, Gustavo, Hugo, Bina, Jonga, Veiga, Carn, Maia, Alves e todos os outros que me apoiaram nesta jornada, mesmo nem sempre na minha maior animação ou presença mas sempre desejando o meu bem. Um agradecimento em especial ao Marçano, completando junto comigo um ciclo que se iniciou na alfabetização e se encerra na graduação como Engenheiro Mecânico, sempre um ajudando o outro.

Obrigado a todos, este trabalho e esta graduação não seria possível sem todos vocês. 


\section{Resumo}

\section{Desenvolvimento de um cubo de roda traseiro para veículo mini-Baja utilizando técnicas de otimização topológica}

Este trabalho apresentará diferentes áreas do conhecimento de Engenharia Mecânica, culminando na obtenção de uma geometria otimizada contra escoamento do cubo de roda traseiro de um veículo mini-Baja visando sua implementação no futuro.

Primeiramente foi estudado o estado da arte do componente afim de determinar os casos de carga atuantes no componente ao longo de sua utilização e seus requisitos mínimos de projeto.

Definidas as solicitações críticas atuantes na peça, foi realizada a aquisição da magnitude das cargas a partir de dados experimentais, modelos computacionais de sistema massa-mola e cálculos analíticos das forças atuantes no veiculo Agama, da Equipe Reptiles Baja PUC-Rio.

De posse dos esforços quantificados e das condições de contorno de operação, foi iniciada a etapa de implementação no software Altair Inspire para execução das simulações estruturais e, posteriormente, a otimização topológica do componente.

\section{Palavras-chave}

Baja; Cubo de Roda; Altair Inspire; Otimização; Cargas. 


\section{Abstract}

\section{Development of a rear wheel hub for a mini-Baja vehicle using topology optimization techniques}

This study will present different areas of Mechanical Engineering knowledge, culminating in obtaining an optimized geometry against runoff of the rear wheel hub of a mini-Baja vehicle aiming its implementation in the future.

First, the state of the art of the component was studied in order to determine the load cases acting on the component during its use and its minimum design requirements.

Once the critical loads acting on the part were defined, the magnitude of the loads was acquired from experimental data, computational models of the spring-mass system and analytical calculations of the forces acting on the vehicle Agama, from the Reptiles Baja PUC-Rio Team.

With the quantified forces and the operating boundary conditions, the Altair Inspire implementation stage was initiated to perform structural simulations and, subsequently, the topological optimization of the component.

\section{Keywords}

Baja; Wheel Hub; Altair Inspire; Optimization; Loads. 


\section{Sumário}

1 Introdução $\quad 8$

2 Projeto de Sistemas Veiculares $\quad 9$

2.1 Sistema de Suspensão 10

2.2 Sistema de Transmissão 12

3 Revisão Bibliográfica $\quad 14$

3.1 Casos de Carga 14

$\begin{array}{ll}3.2 & \text { Condições de Contorno } \\ \end{array}$

4 Aquisição de Esforços $\quad 17$

$\begin{array}{lll}4.1 & \text { Bump } & 17\end{array}$

$\begin{array}{ll}4.2 \text { Curva Crítica } & 19\end{array}$

4.3 Torque Máximo 21

5 Metodologia 23

5.1 Aplicação de cargas e apoios 24

5.2 Geometria Base 27

$\begin{array}{ll}5.3 \text { Malha de Simulação } & 28\end{array}$

6 Resultados Obtidos $\quad 31$

6.1 Otimização Topológica 32

6.2 Geometria Final 35

$\begin{array}{lll}7 & \text { Conclusões } & 38\end{array}$

A Código MATLAB para as contas executadas $\quad 40$ 


\section{Lista de figuras}

1.1 Veículo atual da Equipe Reptiles, o protótipo Naja 8

2.1 Montagem Traseira 9

2.2 Modelo de $\frac{1}{4}$ de carro com 2 graus de liberdade [1] 11

2.3 Diagrama de forças em situação de curva, vista traseira [2] 12

2.4 Fluxo de potência do veículo, do motor as rodas 13

4.1 Resposta oscilatória no Pneu Traseiro Esquerdo 18

4.2 Representação das forças atuantes em caso de Bump 18

4.3 Teste de Skidpad para determinação de velocidade Crítica 19

4.4 Representação das forças atuantes em caso de Curva Crítica 21

4.5 Representação das forças atuantes em caso de Torque Máximo 22

5.1 Remoção dos alivios mássicos previamente utilizados pela equipe 23

5.2 Cubos com flange de conexão com $4 \mathrm{~mm}, 8 \mathrm{~mm}$ e $20 \mathrm{~mm}$ de espessura, respectivamente 24

5.3 Apoio aplicado para os casos de Bump e Curva Crítica 25

5.4 Apoio aplicado para o caso de Torque Máximo 25

5.5 Cargas aplicadas no Cubo de Roda para o Caso de Bump 26

5.6 Cargas aplicadas no Cubo de Roda para o caso de Curva Crítica 26

5.7 Cargas aplicadas no Cubo de Roda para o caso de Torque Máximo 27

5.8 Análise estática da geometria base sendo estudada 27

5.9 Gráfico Tensão Máxima X Número de Elementos de convergência de malha da flange com $20 \mathrm{~mm}$ de espessura 29

5.10 Gráfico Tensão Máxima X Número de Elementos de convergência de malha da flange com $4 \mathrm{~mm}$ de espessura 30

6.1 Análise estática das geometrias com flange de espessura $20 \mathrm{~mm}$ e $10 \mathrm{~mm}$, respectivamente

6.2 Análise estática das geometrias com flange de espessura $6 \mathrm{~mm}$ e 4 $\mathrm{mm}$, respectivamente

6.3 Otimização topológica das geometrias com flange de espessura 4 $\mathrm{mm}$ e $5 \mathrm{~mm}$, respectivamente

6.4 Otimização topológica das geometrias com flange de espessura 6 $\mathrm{mm}$ e $7 \mathrm{~mm}$, respectivamente

6.5 Otimização topológica das geometrias com flange de espessura 8 $\mathrm{mm}$ e $10 \mathrm{~mm}$, respectivamente

6.6 Otimização topológica das geometrias com flange de espessura 15 $\mathrm{mm}$ e $20 \mathrm{~mm}$, respectivamente

6.7 Variação da massa otimizada em função da espessura da flange do cubo de roda

6.8 Otimização topológica das geometrias com flange de espessura 20 $\mathrm{mm}$

6.9 Geometria otimizada do Cubo de Roda Traseiro 36

6.10 Análise estrutural do componente otimizado 37 


\section{Lista de tabelas}

4.1 Cargas para a análise do caso de Bump 19

4.2 Parâmetros utilizados no teste de Skidpad 19

4.3 Forças resultantes obtidas no teste de Skidpad 20

4.4 Parâmetros geométricos do Protótipo Agama 20

4.5 Cargas para a análise do caso de Curva Critica 21

4.6 Parâmetros do Sistema de Transmissão do Protótipo Agama 22

4.7 Cargas para a análise do caso de Torque Máximo 22

5.1 Convergência de Malha para o Cubo com flange de $20 \mathrm{~mm}$ de espessura 28

5.2 Convergência de Malha para o Cubo com flange de $4 \mathrm{~mm}$ de espessura 29

6.1 Redução mássica das diferentes geometrias após o processo de otimização

6.2 Comparativo dos resultados obtidos 37 


\section{Introdução}

Este trabalho tem como objetivo desenvolver o cubo de roda traseiro do protótipo Agama, o próximo a ser fabricado pela Equipe Reptiles Baja PUC-Rio. O veículo da classe Baja SAE (Society of Automotive Engineers) foi inteiramente desenvolvido por estudantes de diferentes cursos da PUCRio, participando anualmente de duas competições sancionadas pela SAE Brasil (1994), ramo criado pela SAE International (1905). Abrangendo desafios dinâmicos e teóricos, avaliados por engenheiros do ramo automobilístico, as competições nacionais e regionais põe a prova os protótipos construídos por equipes de todo Brasil dentro do mesmo Regulamento Técnico (RATBSB) [3].

Dentro do universo de competições automotivas, é de suma importância o constante investimento em aprimoramentos diversos de um veículo. Melhorias em seu comportamento dinâmico ou capacidade estrutural de seus componentes são responsáveis pela otimização da performance durante uma prova. Dessa forma, ajustes em motores, dimensionamento de suspensões e redução mássica de componentes são alguns dos diferenciais entre um possível campeão e o último colocado.

Este trabalho consiste na utilização de técnicas de modelagem de sistemas para determinação dos esforços no veículo, simulação de componentes estruturais para determinação das tensões atuantes no componente e utilização do método de otimização topológica para gerar uma geometria "ótima” de um cubo de roda traseiro de veículo Baja contra escoamento a ser usada como referência para a equipe.

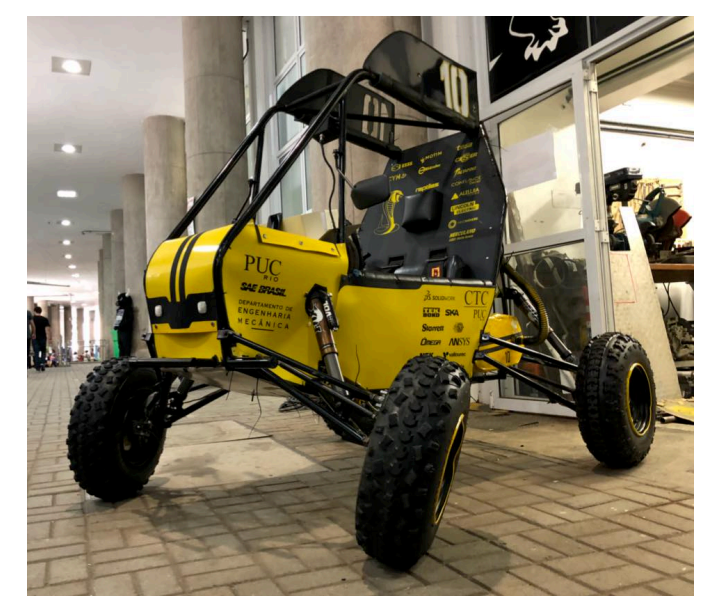

Figura 1.1: Veículo atual da Equipe Reptiles, o protótipo Naja 


\section{2}

\section{Projeto de Sistemas Veiculares}

Um veículo deve ser considerado como um conjunto de sistemas mecânicos compostos por subsistemas distintos que interagem entre si dinamicamente. Abrangendo diferentes técnicas e áreas de estudo, é da competência do engenheiro automotivo analisar as características estruturais e dinâmicas de cada componente, entender sua influência dentro do subsistema e sua interação com demais setores e, por fim, cumprir os requisitos propostos no projeto.

No caso do veículo a ser estudado, o Agama é dividido pela Equipe Reptiles em cinco subsistemas. Os membros da equipe são responsáveis pelo projeto de Suspensão e Direção, Trem de Força, Freio, Eletrônica e Ergonomia e Design. Esta divisão é feita para possibilitar o maior aprofundamento dos estudantes nos conhecimentos dos respectivos subsistemas, porém, é de fundamental importância que ocorra a interação entre os responsáveis do projeto a fim de alcançar as metas estabelecidas pelas competições e pela própria equipe.

Dentro do presente trabalho ficará evidente a interação entre os subsistemas de trem de força e suspensão. O componente a ser estudado, o cubo de roda traseiro, é responsável pela transmissão do torque e rotação gerados no trem de força para roda do veículo na suspensão traseira.

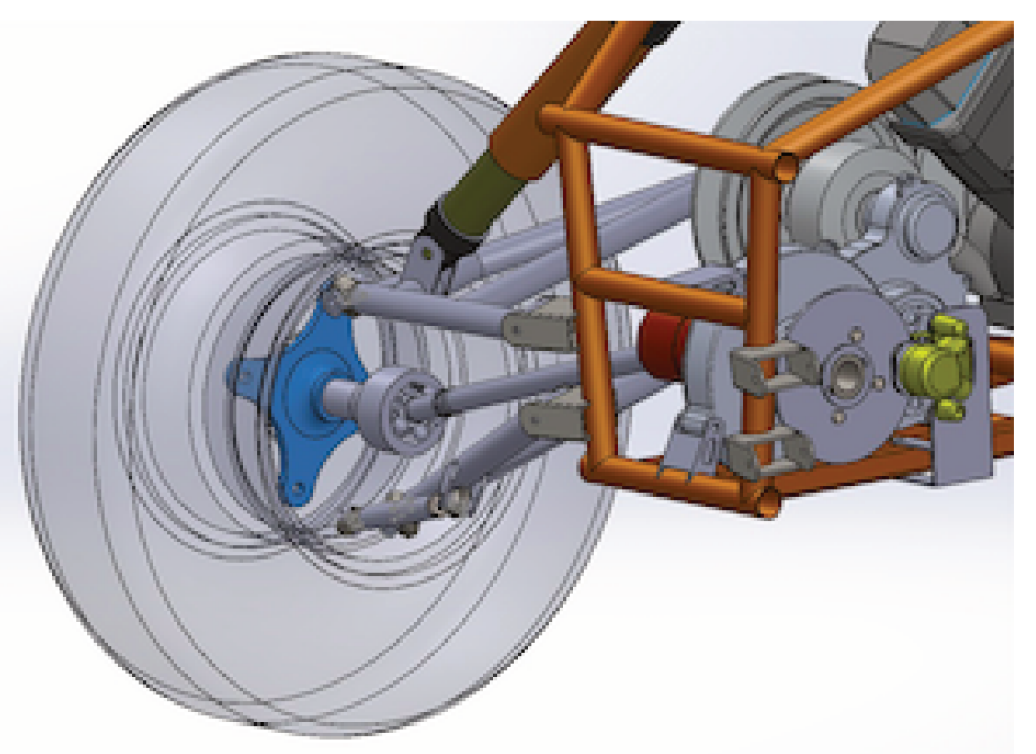

Figura 2.1: Montagem Traseira 
Como é possível observar, o cubo de roda é acoplado a roda do veículo por conexões aparafusadas e ao semi-eixo to tipo homocinética por conexão estriada. Portanto, o presente estudo deve analisar os esforços provenientes de diversas solicitações de dois subsistemas para satisfazer suas condições de trabalho.

\section{1}

\section{Sistema de Suspensão}

O sistema de suspensão, de qualquer tipo de veículo, tem como principal função a manutenção do contato pneu-solo durante toda a solicitação de trabalho. Além disso, é responsável por absorver e dissipar os impactos causados pelas excitações do terreno a fim de proporcionar conforto e segurança ao usuário. Seus componentes são solicitados em diversos casos de trabalho e interagem entre si de forma distinta para cada caso.

Portanto, é de fundamental importância que o sistema, composto por molas, amortecedores, corpos rígidos e conexões, seja dimensionado de acordo com os esforços mecânicos solicitantes (provendo segurança estrutural). É possível utilizar diferentes formas de modelagem para representar o sistema de suspensão e quantificar os esforços atuantes em seus componentes.

O estudo dos esforços pode ainda ser subdividido com relação ao sentido das acelerações do corpo do veículo e suas interações. A divisão entre aceleração vertical, longitudinal e lateral, tendo como referência o centro de gravidade do conjunto veículo-piloto, permite analisar de forma individual e global os esforços em cada direção.

Além de cálculos analíticos e geométricos, a suspensão veicular pode ser representada por meio de modelos dinâmicos vibracionais massa-molaamortecedor (conhecido como $\frac{1}{4}$ de veículo), permitindo a obtenção dos esforços em cada corpo representado.

\subsection{1}

\section{Modelo de $\frac{1}{4}$ de veículo}

A modelagem de sistemas massa-mola-amortecedor pode ser feita com diferentes complexidades, diretamente relacionada ao número de graus de liberdade no sistema e fidelidade dos esforços em cada corpo. Para fins de representação de sistemas de suspensão veicular, são necessários dois corpos (dois graus de liberdade) para que seja possível distinguir os movimentos e esforços atuantes no chassi e nas rodas. A introdução de mais graus de liberdade e mais dados do sistema permite a aproximação do modelo com a realidade, porém, este aumento da complexidade na modelagem deve estar de acordo 
com a necessidade de precisão e fidelidade dos dados afim de reduzir custos computacionais e operacionais.

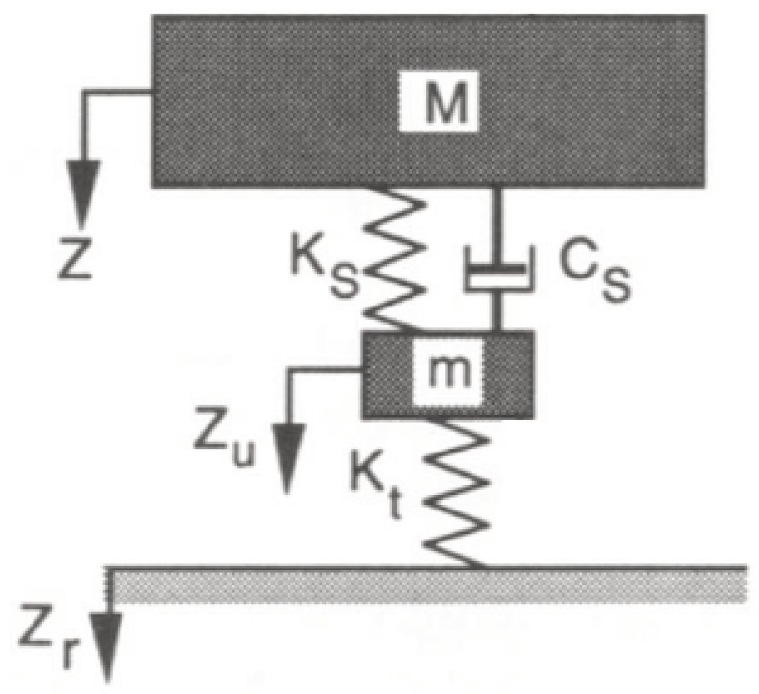

Figura 2.2: Modelo de $\frac{1}{4}$ de carro com 2 graus de liberdade [1]

A Figura 2.2 representa o modelo de $\frac{1}{4}$ de carro contendo 2 graus de liberdade, onde é avaliado o deslocamento vertical de 2 corpos em relação às excitações provocadas pelo solo. O referencial Z representa o grau de liberdade do chassi de massa M (que será estabelecida futuramente como massa suspensa). O referencial Zu representa o grau de liberdade do conjunto de roda do veículo de massa m (futuramente estabelecida como massa não-suspensa).

A transmissão de esforços do solo para a roda é feita por meio da representação do pneu como a mola de constante de rigidez Kt. Os deslocamentos relativos entre os corpos, e consequentemente transmissão dos esforços, entre o chassi e as rodas dependem da constante de rigidez Ks e coeficiente de amortecimento Cs, representando a mola e o amortecedor do sistema de suspensão respectivamente.

\subsection{2}

\section{Transferência Lateral de Carga}

Em uma situação de esterçamento, a aceleração lateral no centro de gravidade do veículo como reação da força centrípeta provoca a transferência de carga do lado interno para o lado externo. Este comportamento provoca o rolamento do chassi em torno do eixo longitudinal podendo, em casos extremos, causar o tombamento em curvas com alta velocidade, onde o equilíbrio não é satisfeito. 
Este comportamento pode ser facilmente exemplificado em casos do cotidiano. Os ônibus, por exemplo, por terem um centro de gravidade bem elevado, permitem que seus passageiros sintam a aceleração de forma excessiva. Carros de Fórmula 1, que necessitam realizar curvas em alta velocidade, tem seu centro de gravidade o mais próximo possível do solo, entre outros motivos, para reduzir o comportamento de rolagem do chassi.

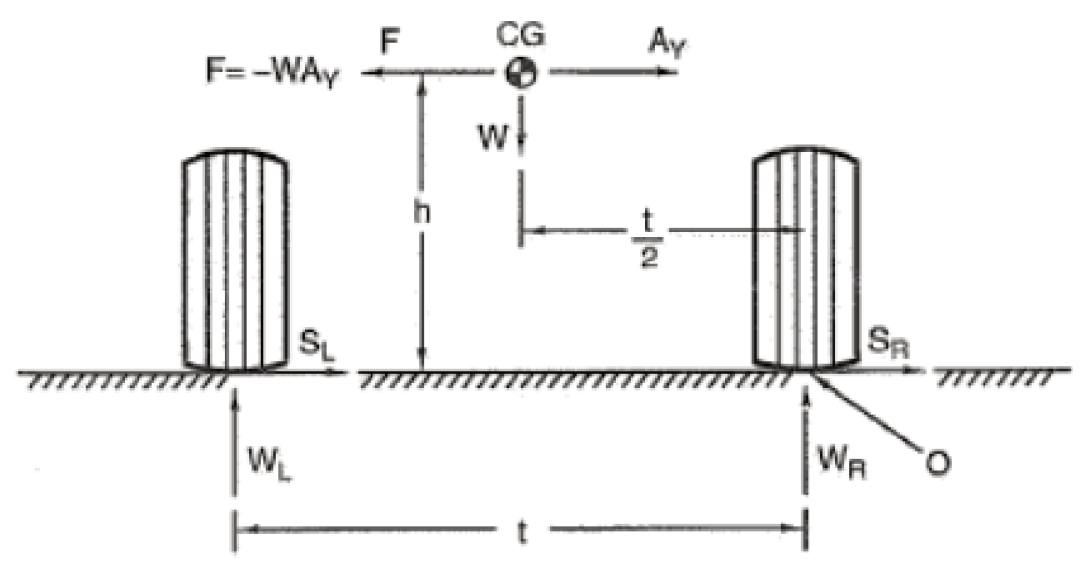

Figura 2.3: Diagrama de forças em situação de curva, vista traseira [2]

A Figura 2.3 permite a visualização dos esforços atuantes no veículo e, por meio do balanço de forças em torno de um dos pontos de contato do pneusolo, podemos estimar o acréscimo de carga em uma roda e, consequentemente, a redução de carga na outra. Em um caso de tombamento, as rodas internas a curva estarão sem carga vertical.

\section{2}

Sistema de Transmissão

O sistema de trem de força é responsável por transmitir a potência e torque gerados pelo motor até as rodas. No caso do protótipo mini-Baja sendo estudado, a transmissão é feita na seguinte sequência: 


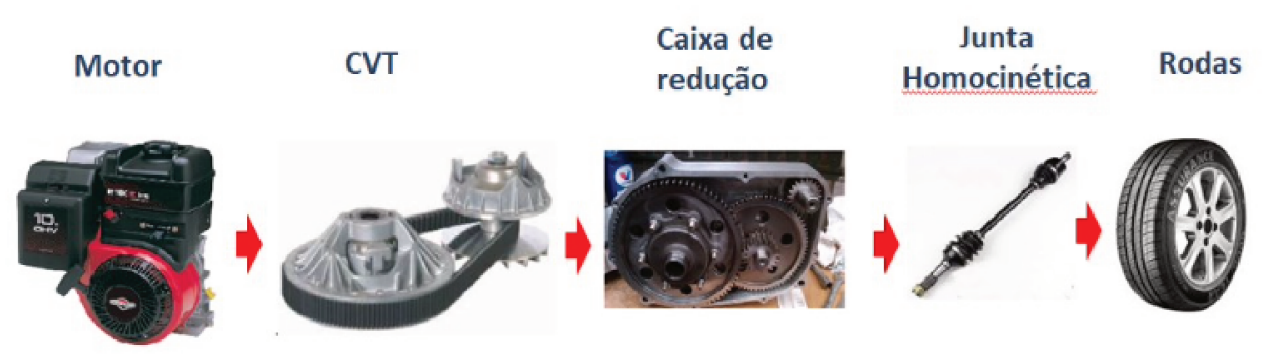

Figura 2.4: Fluxo de potência do veículo, do motor as rodas

O eixo do motor está conectado a uma CVT (do inglês, Continuously Variable Transmission) na "polia motora". Por meio de uma correia dentada ligada a "polia movida", a potência é transmitida para a caixa de redução. No eixo de saída da caixa, a potência e transmitida para um semi-eixo homocinética e, por fim, chega as rodas por meio do cubo de roda. Esta configuração é customizável, permitindo um torque variável até a roda dependendo da solicitação do percurso.

Dessa forma, a análise do caminho de potência nos permite encontrar os esforços no cubo de roda traseiro provenientes do trem de força. 


\section{3}

\section{Revisão Bibliográfica}

Neste capítulo será apresentado o estado da arte do tema estudado em pesquisas previamente publicadas. A partir desta revisão, serão ponderados os diferentes aspectos necessários para este trabalho como condições de contorno, forçamentos e simulações estruturais.

Inicialmente, foram estudados os diferentes casos de carga e condições de contorno a serem aplicados no componente. Essas condições serão posteriormente implementadas no software de modelagem e simulação escolhido para o estudo.

\section{1}

\section{Casos de Carga}

A partir do estudo da dinâmica veicular aplicado ao veículo mini-Baja alinhado aos presentes trabalhos sobre o tema, foram definidos como casos de carga as seguintes situações: Curva crítica (iminência de capotamento por rolamento), Torque Máximo proveniente do motor e transposição de obstáculo de 400 milímetros de altura (requisitos de projeto no regulamento).

O caso de curva crítica apresentada por Matilde [4] contempla o fenômeno de transferência lateral de carga em situação extrema, em imininência de capotamento. Derivada da força centrípeta no centro de gravidade do veículo, as cargas atuantes no componente tem como entrada no sistema o ponto central da banda do pneu externo em contato com o solo. Conforme demonstrado na Figura 2.3, a força de entrada no pneu possui uma componente vertical de reação da força peso e uma componente horizontal proveniente do atrito entre o pneu e o solo direcionada ao centro da curva. A aplicação do forçamento proposto no trabalho não considera o contato entre os parafusos e a face dos furos de fixação. Portanto, estas cargas serão aplicadas ao cubo em forma de momento na face da flange (oriundas da força horizontal) e forças de contato entre as faces dos furos e os parafusos de fixação na roda (oriundas da força vertical).

De acordo com o Regulamento Técnico [3], o protótipo deve ser capaz de superar uma rampa de inclinação de 30 graus a partir da inércia. Para isso, Roehrs [5], considerou o torque máximo proveniente do motor para o dimensionamento de caixa redutora e CVT do protótipo, de forma a garantir o cumprimento desta restrição e transmissão de torque suficiente à roda para subir a rampa. A partir da metodologia utilizada, será considerado o valor 
máximo do torque gerado pelo motor, assim como a redução do sistema e suas perdas de eficiência para estimar o valor do torque a ser aplicado ao eixo central do componente, não levando em consideração a região estriada do mesmo. Além disso, este caso também considera a força de contato entre os parafusos e a face dos furos considerando apenas a massa em repouso do veículo.

O caso apresentado por Novis [6] e ratificado como requisito de projeto pelo Regulamento Técnico [3] considerou a sobreposição de um obstáculo semelhante a um tronco de árvore com $400 \mathrm{~mm}$ de diâmetro. Assim como no caso de curva crítica, o ponto de entrada das forças no sistema é relativo ao eixo central da banda do pneu em contato com o obstáculo de forma vertical. Desta forma, a aplicação das cargas verticais do caso de curva é representado da mesma forma que no caso convenientemente chamado de "Bump", considerando forças de contato entre as faces dos furos e os parafusos de fixação.

\section{2}

\section{Condições de Contorno}

O trabalho apresentado por Lima [7] contemplou a análise do cubo de roda traseiro assim como a manga de eixo na qual o cubo é acoplado. Apesar da diferença geométrica dos componentes, a consideração do caso de carga do torque proveniente do motor utilizada pelo autor pode ser adequada ao presente estudo. Como condição de fixação do cubo na roda do veículo, foi definido o apoio nos furos do cubo de roda restringindo os movimentos de translação e rotação em torno de todos os eixos, fixando o cubo na roda do veículo. Tal restrição será utilizada nas simulações estruturais deste caso de carga visto que representa de forma satisfatória a fixação por parafusos do componente em relação ao torque aplicado no eixo central descrito no item anterior, sem que fosse necessário implementar novos componentes na simulação.

Apesar de estudar o comportamento do cubo de roda dianteiro em veículo mini-Baja, o trabalho produzido por Matilde [4] pode ser adequado ao estudo do cubo traseiro por suas semelhanças quanto à geometria e solicitações de carga. O caso de curva crítica apresentado pela mesma é atuante tanto no eixo dianteiro quanto traseiro. Seu trabalho considerou como apoio os rolamentos conectados ao eixo da manga dianteira, restringindo rotação e translação em torno de todos os eixos exceto no eixo axial do furo. É possivel então traçar um paralelo ao eixo traseiro da homocinética conectado ao cubo de roda traseiro e adotar as mesmas condições de restrição propostas por Matilde [4], que representam de forma satisfatória o caso estudado. 
Para o último caso avaliado, de sobreposição de um obstáculo, as condições de contorno definidas por Matilde [4] foram definidas de forma análoga ao caso de curva crítica considerando que a origem dos esforços no sistema é proveniente do mesmo ponto, diferindo apenas em sua intensidade e direção. Portanto, as restrições impostas ao sistema no caso de carga anterior pode ser replicado para o caso de "Bump".

Por fim, foi analisado o tipo de malha utilizado nas analises numéricas e estruturais a serem implementadas no software escolhido. Conforme apresentado em Novis [6] e Matilde [4], elementos do tipo tetraédrico de primeira ordem concentrados em regiões críticas são habitualmente utilizados para determinar com precisão as tensões e deformações atuantes no componente com geometria irregular. É importante ressaltar que ambos os trabalhos realizam um teste de convergência de malha para alcançar resultados mais precisos e reduzir o custo computacional atrelado à utilização de malhas com alto refinamento (elementos tetraédricos muito pequenos), portanto, esta metodologia também será utilizada neste trabalho. 


\section{Aquisição de Esforços}

Para a determinação dos esforços atuantes no componente para cada caso de carga citado anteriormente foi necessário desenvolver um modelo matemático para representação da dinâmica do sistema.

Considerando que o escopo principal deste trabalho não é a dinâmica do sistema de suspensão, optou-se pela adaptação do sistema vibratório de 2 graus de liberdade elaborado por Novis [6] de acordo com um modelo de 1/4 de carro para o veículo anterior da equipe (Naja). Este software permite obter respostas oscilatórias da dinâmica vertical do veículo.

A adaptação do modelo apresentado no Apêndice A consistiu na adequação das diferenças geométricas entre os protótipos como bitola e entre-eixo. A utilização deste software em Matlab foi possível pois o veículo Naja compartilha muitos de seus componentes com o protótipo Agama, permitindo valores de respostas similares entre os dois veículos.

\section{1}

\section{Bump}

Após a implementação dos parâmetros de entrada no script, foi necessário determinar a entrada no sistema de funções de transferência para obtermos as saídas como cargas na massa não-suspensa (pneu) e massa suspensa (amortecedor).

Como explicitado no item 3.1, este caso de carga representa a transposição de um obstáculo de 400 mm de altura prevista no Regulamento Técnico [3], portanto, para simular esta situação foi utilizado uma entrada do tipo rampa da mesma altura do obstáculo.

Na Figura 4.1 podemos observar graficamente a resposta oscilatória de carga no pneu traseiro esquerdo após a passagem pelo obstáculo. Com o intuito de dimensionar o componente do cubo de roda contra escoamento, foi coletado o valor máximo de carga (pico mais elevado) para futuramente implementar na simulação estrutural do software Altair Inspire. 


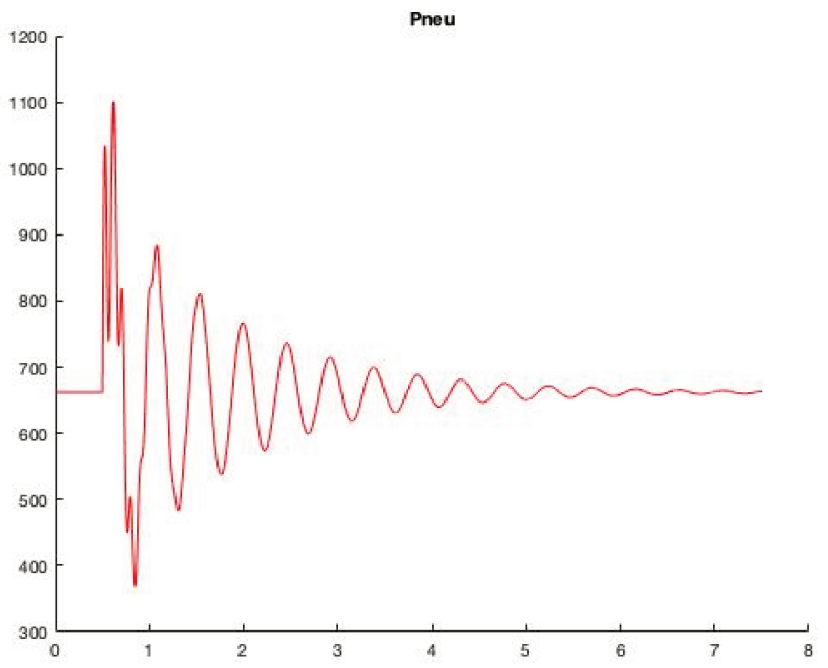

Figura 4.1: Resposta oscilatória no Pneu Traseiro Esquerdo

A partir do modelo, foi encontrada a intensidade máxima da força vertical no pneu de $1101 \mathrm{~N}$. Deste valor foi possível calcular a carga vertical a ser aplicada em cada uma das quatro faces dos furos de fixação assim como o momento na face da flange do cubo devido a um offset entre o plano médio do pneu e a face do cubo de roda. As cargas podem ser representadas conforme a Figura 4.2 e quantificadas de acordo com a tabela 4.5:

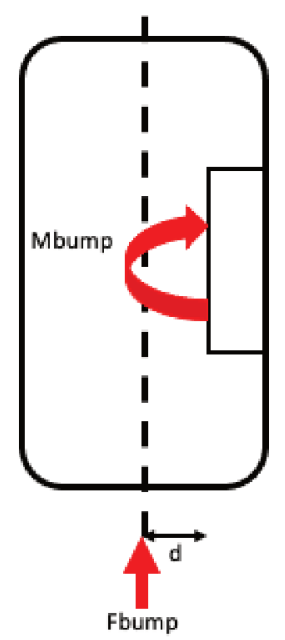

Figura 4.2: Representação das forças atuantes em caso de Bump 


\begin{tabular}{lc} 
Cargas & Intensidade \\
\hline Força no Pneu & $1101 \mathrm{~N}$ \\
\hline Força na face de cada furo & $275,25 \mathrm{~N}$ \\
\hline Momento na face do Cubo & $9,91 \mathrm{~N} . \mathrm{m}$ \\
\hline
\end{tabular}

Tabela 4.1: Cargas para a análise do caso de Bump

\section{2}

\section{Curva Crítica}

Para este caso de carga foi necessário combinar os valores encontrados no modelo e cálculos análiticos apresentado por Milliken [2] e demonstrados no item 2.1.2 para determinar a intensidade das forças atuantes no componente. Além disso, foram utilizados também os dados fornecidos pela equipe obtidos durante a realização de um Teste de Skidpad para determinação da velocidade crítica em curvas (iminência de tombamento).

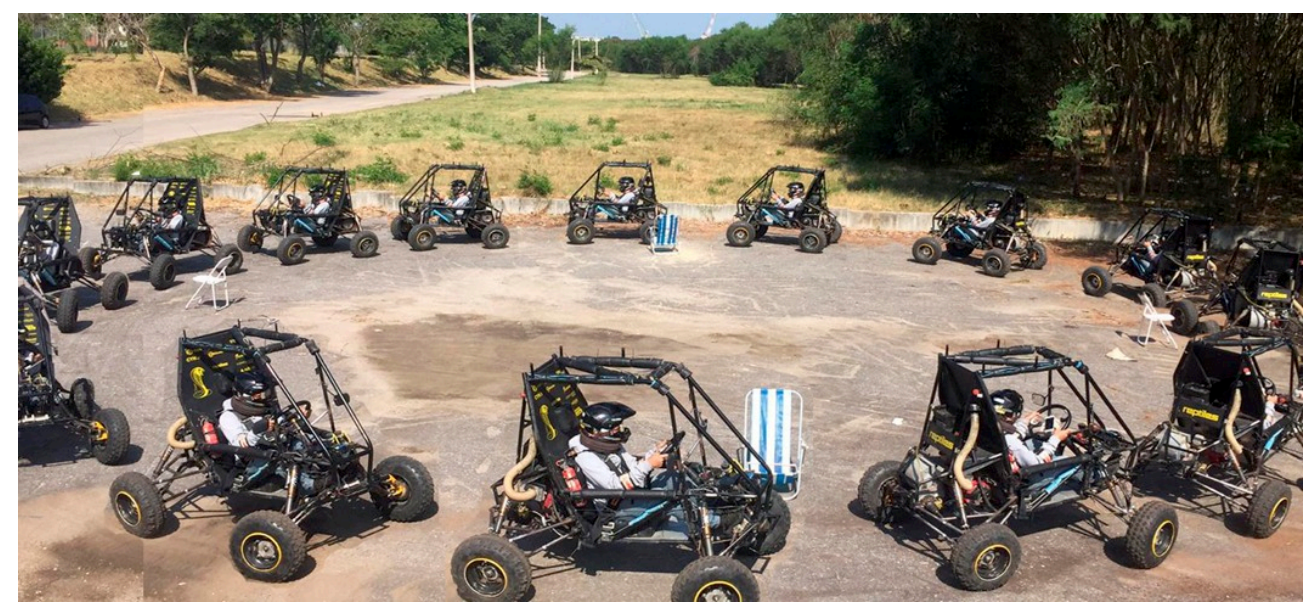

Figura 4.3: Teste de Skidpad para determinação de velocidade Crítica

\begin{tabular}{lc} 
Parâmetros & Valores \\
\hline Raio de Curva & $7 \mathrm{~m}$ \\
\hline Velocidade Crítica & $30 \mathrm{Km} / \mathrm{h}$ \\
\hline Massa do Veículo & $250 \mathrm{Kg}$ \\
\hline
\end{tabular}

Tabela 4.2: Parâmetros utilizados no teste de Skidpad

A partir dos resultados encontrados no teste acima, e do modelo análitico apresentado no item 2.1.2, foi possível calcular os valores da força centrípeta 
atuante no centro de gravidade do veículo e as forças equivalentes em cada pneu considerando a simetria da massa em torno do eixo longitudinal e $54 \%$ da massa concentrada no eixo traseiro do veículo.

\begin{tabular}{lc} 
Cargas & Intensidade \\
\hline Força Centripeta no CG & $2480,2 \mathrm{~N}$ \\
\hline Força horizontal no pneu esquerdo & 669,6 \\
\hline
\end{tabular}

Tabela 4.3: Forças resultantes obtidas no teste de Skidpad

Além da força horizontal encontrada acima, foi calculado o incremento de carga no pneu externo (e decréscimo de carga no pneu interno) por meio da fórmula de transferência vertical de carga demonstrada em Milliken [2], novamente considerando $54 \%$ da carga no eixo traseiro, ou seja:

$$
\Delta W_{L}=\frac{F_{c p} \times h}{t}=565 N
$$

\begin{tabular}{ll} 
Parâmetros & Valores \\
\hline Altura do CG (h) & $0,513 \mathrm{~m}$ \\
\hline Bitola do veículo (t) & $1,216 \mathrm{~m}$ \\
\hline
\end{tabular}

Tabela 4.4: Parâmetros geométricos do Protótipo Agama

A partir dos resultados encontrados para as forças atuantes no contato entre pneu e solo, novamente foi calculado o momento resultante atuante na face do cubo de roda e a carga vertical na face de cada furo, processo semelhante ao caso de Bump. 


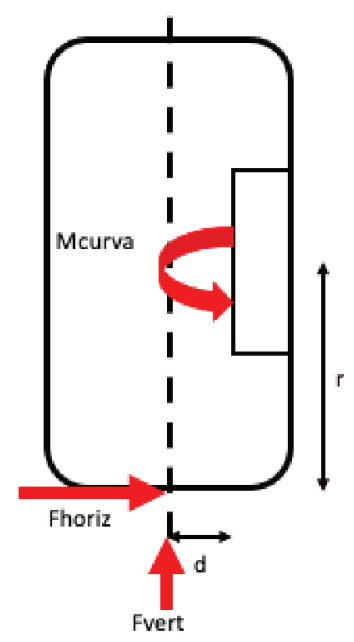

Figura 4.4: Representação das forças atuantes em caso de Curva Crítica

\begin{tabular}{lc} 
Cargas & Intensidade \\
\hline Força na face de cada furo & $306,8 \mathrm{~N}$ \\
\hline Momento na face do Cubo & 149,67 N.m
\end{tabular}

Tabela 4.5: Cargas para a análise do caso de Curva Critica

\section{3}

\section{Torque Máximo}

Por fim, o caso de torque máximo conta com o forçamento vertical nas faces dos furos devido ao peso do veículo e torque gerado pelo sistema de transmissão que chega ao cubo.

A carga decorrente do peso do veículo pode ser facilmete obtida no modelo matemático sem a introdução de perturbações no sistema. O torque foi calculado considerando o torque máximo do motor, a redução máxima possível da CVT e a redução da caixa redutora do protótipo Agama. De acordo com Roehrs [5], é necessário considerar a eficiência do sistema em torno de 85\%, ou seja:

$$
\Delta T_{\text {Max }}=T_{\text {motor }} \times \operatorname{Red}_{C V T} \times \operatorname{Red}_{\text {caixa }} \times \eta
$$




\begin{tabular}{lc} 
Parâmetros & Valores \\
\hline Torque do Motor $\left(T_{\text {motor }}\right)$ & 18,7 N.m \\
\hline Redução máxima da CVT $\left(\operatorname{Red}_{C V T}\right)$ & 3 \\
\hline Redução máxima da Caixa de Redução $\left(\operatorname{Red}_{\text {caixa }}\right)$ & 9.71 \\
\hline Eficiência do Sistema $(\eta)$ & $85 \%$ \\
\hline
\end{tabular}

Tabela 4.6: Parâmetros do Sistema de Transmissão do Protótipo Agama

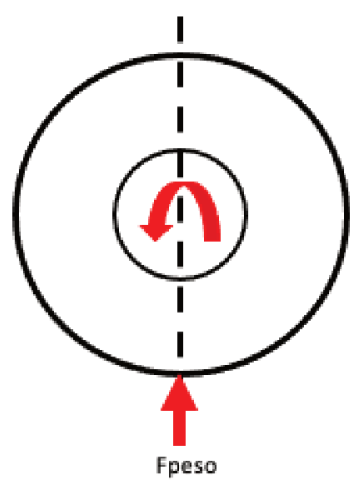

Figura 4.5: Representação das forças atuantes em caso de Torque Máximo

\begin{tabular}{lc} 
Cargas & Intensidade \\
\hline Força do Peso do Veículo & $662,2 \mathrm{~N}$ \\
\hline Força na face de cada furo & $165,5 \mathrm{~N}$ \\
\hline Torque Máximo no Cubo de Roda & $463,02 \mathrm{~N} . \mathrm{m}$ \\
\hline
\end{tabular}

Tabela 4.7: Cargas para a análise do caso de Torque Máximo 


\section{Metodologia}

O presente capítulo apresentará a metodologia utilizada para aplicação dos esforços e condições de contorno estudados no capítulo anterior no software computacional Altair Inspire para realizar as simulações estruturais. Será também apresentado o estudo de refinamento de malha realizado com o intuito de mitigar as variações de tensões resultantes.

A peça foi então introduzida no software Altair Inspire para execução da análise estática e posteriomente sua otimização. Como o intuito deste trabalho é encontrar uma geometria otimizada utilizando técnicas de otimização topológica, os alívios previamente fabricados pela equipe foram removidos para que outras topologias fossem geradas, obtendo-se um resultado mais realista.
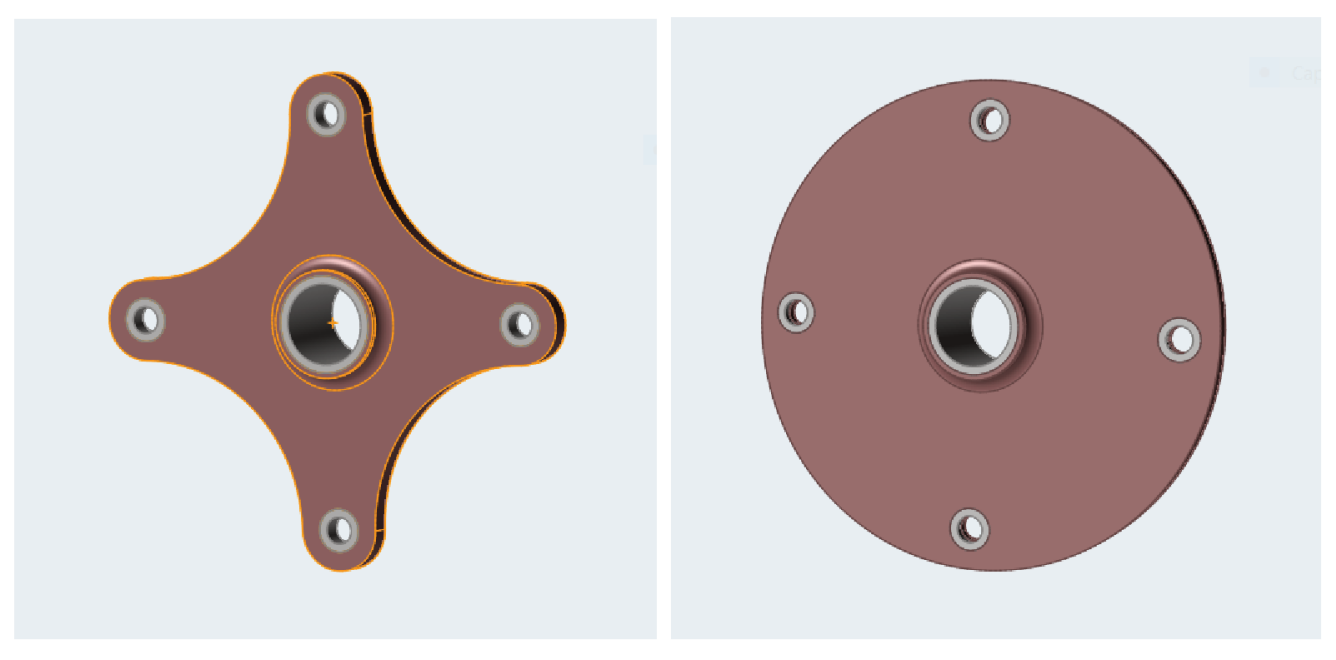

Figura 5.1: Remoção dos alivios mássicos previamente utilizados pela equipe

A fim de avaliar a influência da geometria inicial no resultado final do processo de otimização, será considerado o estudo da variação da espessura da flange de conexão no resultado final. Para isso, serão realizadas análises estruturais, e posteriomente otimizações, de oito geometrias variando a espessura com valores entre 4 e $20 \mathrm{~mm}$ (sendo $8 \mathrm{~mm}$ a espessura original). 


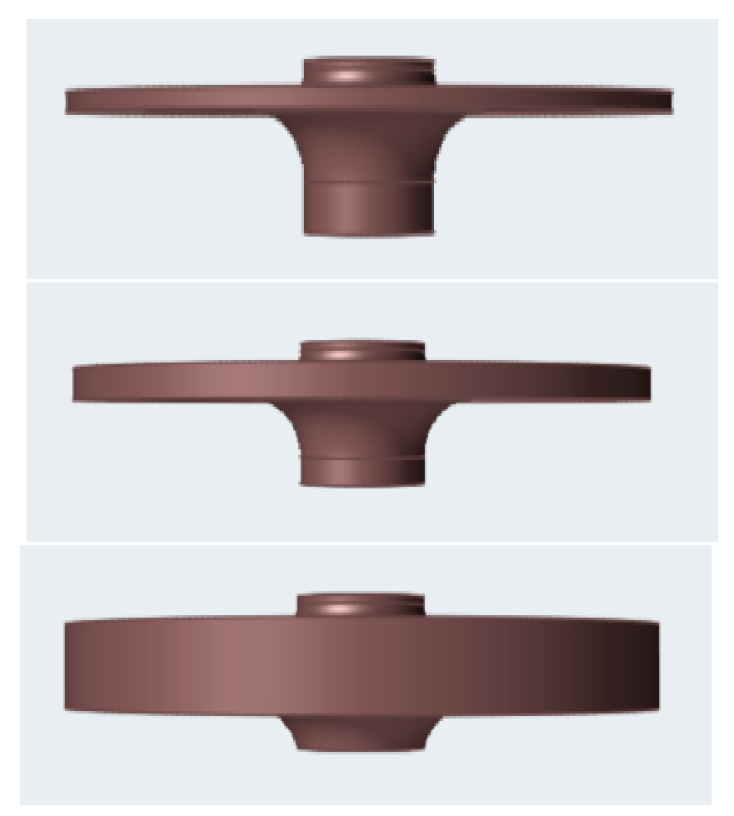

Figura 5.2: Cubos com flange de conexão com $4 \mathrm{~mm}, 8 \mathrm{~mm}$ e $20 \mathrm{~mm}$ de espessura, respectivamente

Este estudo possibilitará comparar os resultados finais e a validade de iniciar o procedimento de otimização topológica com maior volume total, permitindo que o software realize a retirada de material da melhor forma possível.

\section{1}

\section{Aplicação de cargas e apoios}

Com base na pesquisa realizada no Capítulo 3 e da magnitude dos esforços calculados no Capítulo 4 do presente trabalho, iniciou-se o processo aplicação de cargas e apoios no software Inspire.

Para os casos de Bump e curva crítica foi definido o apoio no furo central que acopla o eixo homocinética da transmissão. $\mathrm{O}$ apoio foi aplicado na face interna do furo, restringindo a translação e rotação nos eixos X e Y e permitindo livre rotação e translação no eixo Z, conforme a Figura 5.3. 


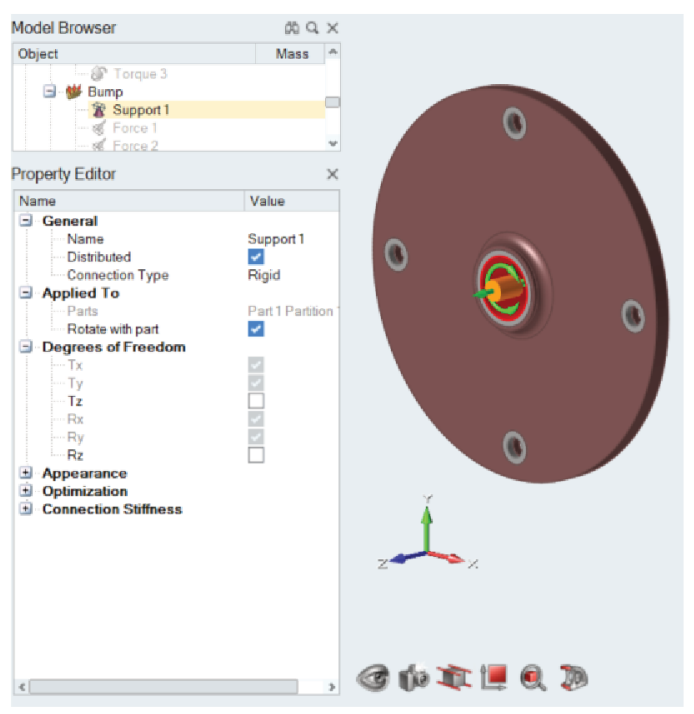

Figura 5.3: Apoio aplicado para os casos de Bump e Curva Crítica

Para o caso de torque máximo, como explicitado no item 3.2, os suportes foram aplicados nas faces internas dos furos de de fixação do cubo na roda. Dessa forma, foram restringidos os movimentos de translação e rotação em todos os eixos, conforme mostrado na Figura 5.4 .

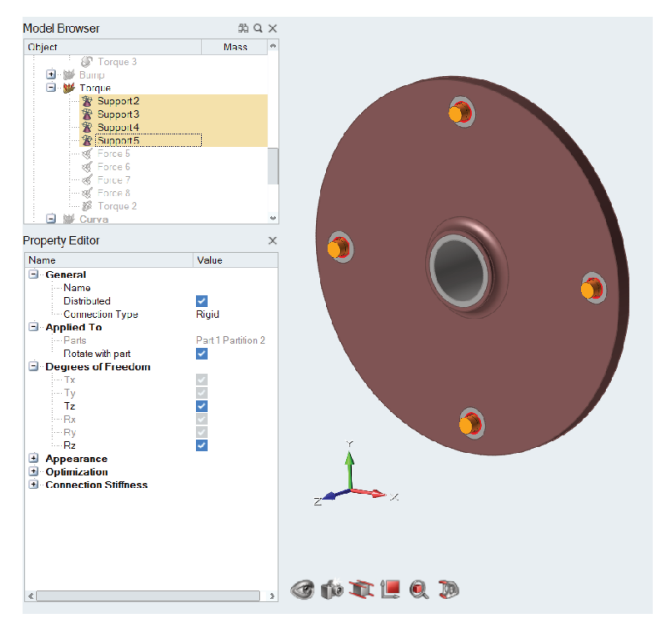

Figura 5.4: Apoio aplicado para o caso de Torque Máximo

Mediante a definição dos suportes para cada caso, foi iniciado o processo de aplicação dos carregamentos apresentados no Capítulo 4.

De acordo com o item 4.1, a força vertical de entrada na base do pneu foi igualmente distribuida entre os quatro parafusos de fixação. Desta forma, as cargas verticais direcionadas para cima foram então aplicadas nas faces internas dos furos. Considerando o offset entre o cubo de roda e o plano central do pneu, 
o momento resultante fa força no pneu foi aplicado na face do cubo (ver Figura $5.5)$.
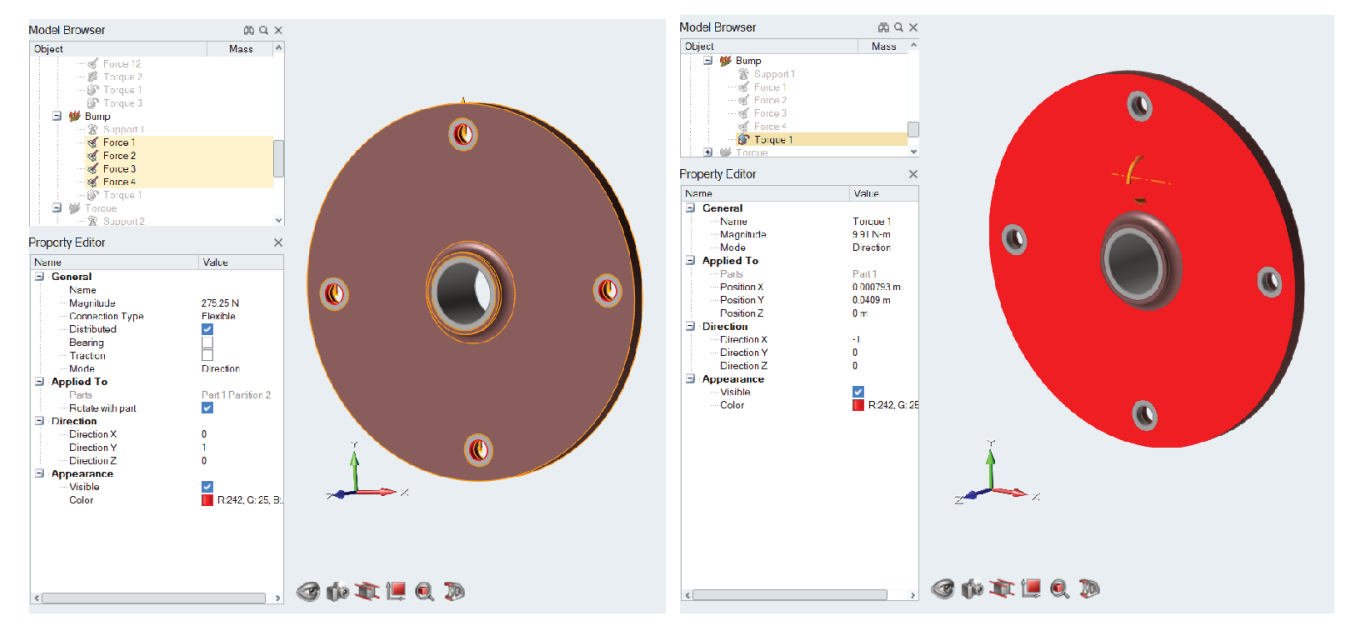

Figura 5.5: Cargas aplicadas no Cubo de Roda para o Caso de Bump

Seguindo a metodologia do item 4.2, os forçamentos no cubo para o caso de curva crítica são semelhantes ao caso de Bump, variando apenas suas intensidades e, no caso do momento aplicado à face, sua orientação devido à força horizontal na base do pneu com direção ao centro da curva (ver Figura $5.6)$.
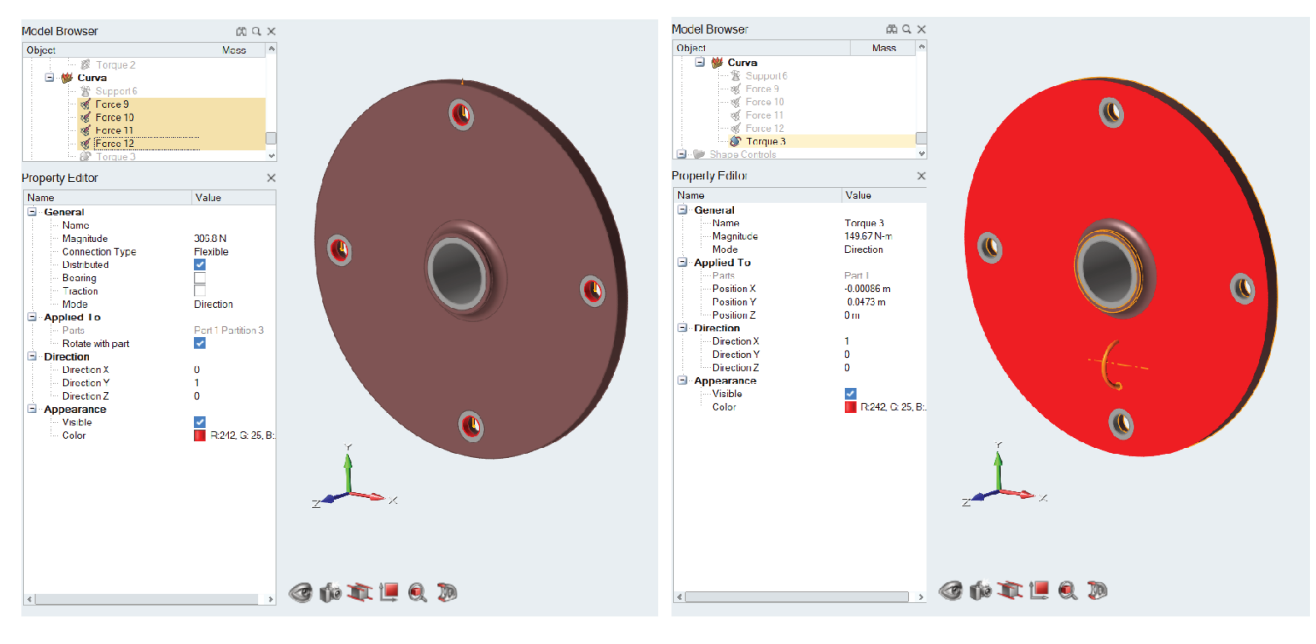

Figura 5.6: Cargas aplicadas no Cubo de Roda para o caso de Curva Crítica

Por fim, seguindo a análise apresentada no item 4.3, as cargas aplicadas na face interna dos furos são o resultado apenas do peso do veículo no pneu traseiro esquerdo. Além disso, o torque gerado pelo sistema de transmissão foi aplicado a face do eixo central, concluindo as cargas atuantes no cubo de roda traseiro em diferentes solicitações (ver Figura 5.7. 

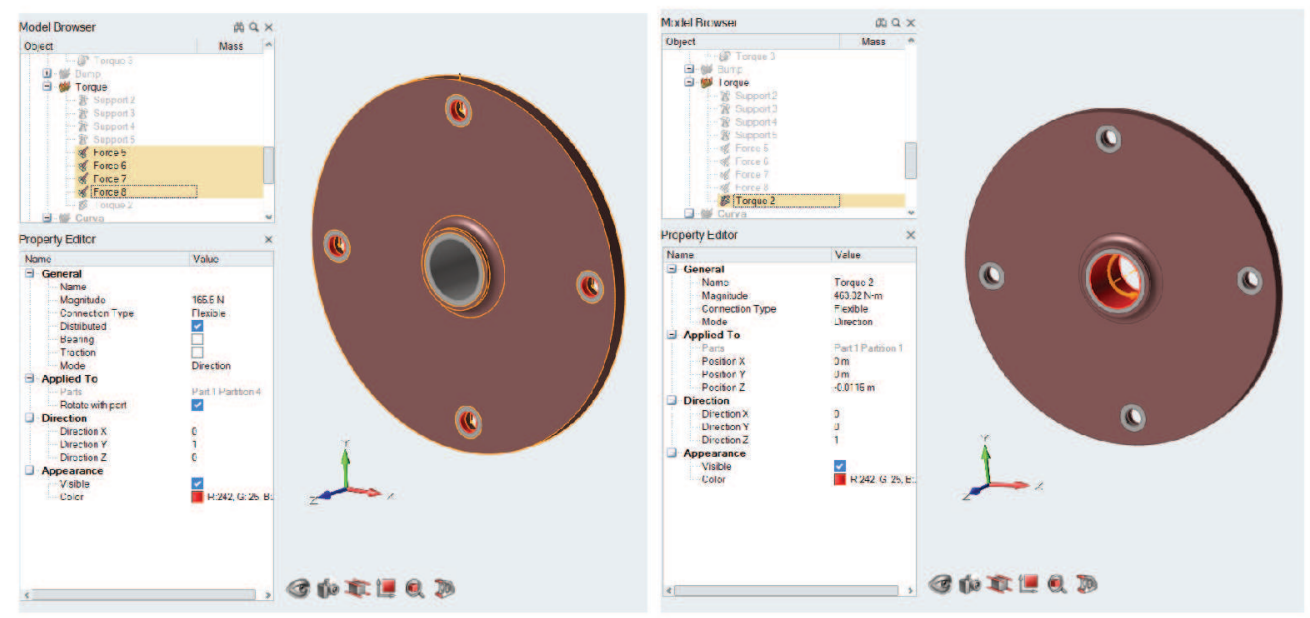

Figura 5.7: Cargas aplicadas no Cubo de Roda para o caso de Torque Máximo

\section{2}

\section{Geometria Base}

A partir dos forçamentos e condições de contorno implementados no software, o cubo em sua geometria base foi analisado visando conhecer as tensões resultantes e seu fator de segurança contra o escoamento. Conhecido os resultados será possível determinar os parametros desejados durante a etapa de otimização para obtenção de um componente mais leve e com fator de segurança contra escoamento adequado. De início, foi utilizada uma malha genérica fornecida pelo software (ilustrada na Figura 5.8) para obtermos resultados com ordem de grandeza próximos do real, possibilitando minimamente uma análise de viabilidade do estudo.
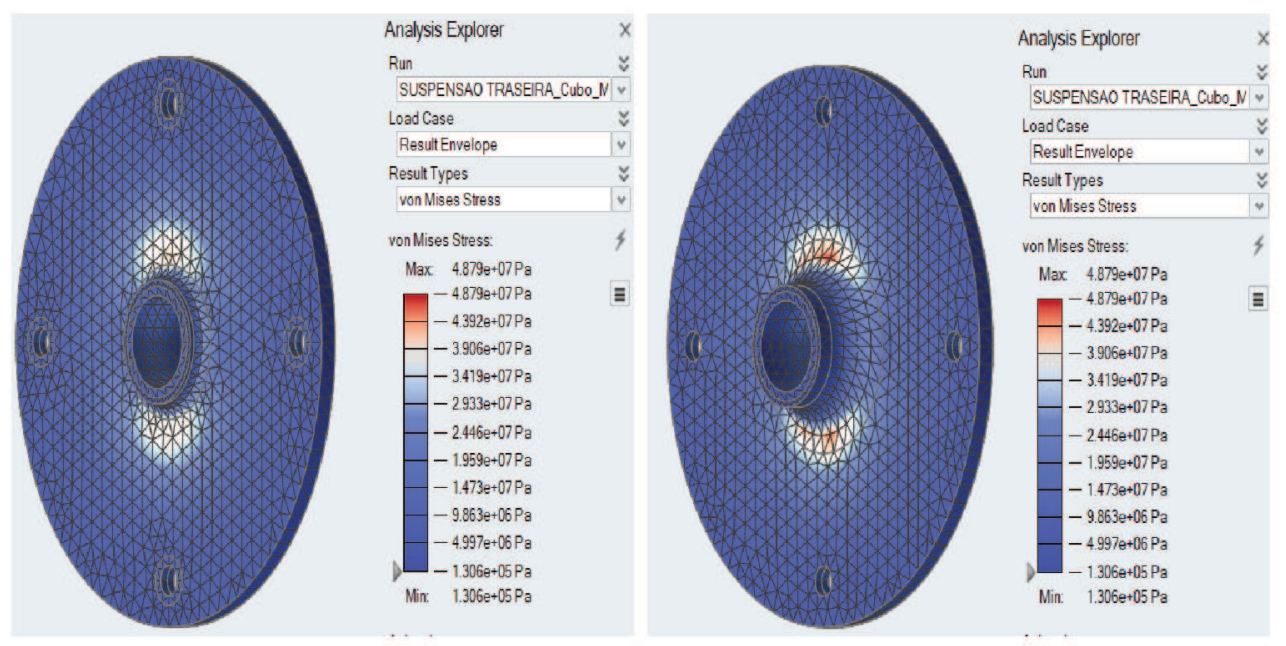

Figura 5.8: Análise estática da geometria base sendo estudada 
Conforme apresentado acima, as máximas tensões resultantes no componente indicam o superdimensioamento do mesmo, com fator de segurança contra o escoamento muito elevado na ordem de 8,48 para o material Alumínio 7075-T6 utilizado. Portanto, é viável a premissa de otimização do componente visando sua redução mássica e manutenção do fator de segurança ao escoamento acima de 2.

\section{3}

\section{Malha de Simulação}

Após a implementação da geometria e das condições de operação do componente no software, foi iniciado o processo para definir a malha de simulação a ser utilizada. O refinamento da malha visa eliminar a variação de tensões e deslocamentos resultantes para diferentes análises estruturais (com número de elementos distintos) e diminuir o custo computacional devido ao número de elementos finais.

O software Altair Inspire possui uma ferramenta de criação de malha genérica, porém, a mesma apresenta elementos com dimensões muito distintas entre si, diminuindo a precisão dos resultados. Em sua versão estudantil, o software utiliza elementos tetraédicros de primeira ordem (TET4) para compor a malha do componente. Seguindo a metodologia adotada por Novis [6] e Matilde [4] explicita no item 3.2, foi implementado um procedimento para refinar a malha de elementos finitos a serem utilizadas nas simulações.

Dessa forma, foi iniciado um procedimento iterativo manual reduzindo o tamanho do elemento gradativamente e coletando as informações da malha e resultados das análises estáticas para definir a malha utilizada. Como o presente trabalho estudará a otimização de oito geometrias distintas (variando a espessura da flange conforme a Figura 5.2), o exercício proposto foi aplicado para os extremos $20 \mathrm{~mm}$ de espessura e $4 \mathrm{~mm}$ de espessura, comparando os resultados e escolhendo a malha mais adequada para uso geral.

Refinamento de Malha - $20 \mathrm{~mm}$ de espessura

\begin{tabular}{lccccccccc}
\hline Tamanho do elemento [mm] & 20 & 15 & 10 & 8 & 7 & 6 & 5 & 4 & 3 \\
\hline Número de Elementos & 1.670 & 3.151 & 5.627 & 8.728 & 11.835 & 15.704 & 23.119 & 37.043 & 72.725 \\
\hline Tensão de Von Mises Máx [MPa] & 21.77 & 20.39 & 19.92 & 24.11 & 24.09 & 26.83 & 27.51 & 29.82 & 30.27 \\
\hline Fator de Segurança & 19.01 & 20.28 & 20.77 & 17.16 & 17.18 & 15.42 & 15.04 & 13.87 & 13.67 \\
\hline
\end{tabular}

Tabela 5.1: Convergência de Malha para o Cubo com flange de $20 \mathrm{~mm}$ de espessura 
Refinamento de Malha - $4 \mathrm{~mm}$ de espessura

\begin{tabular}{lccccccccc}
\hline Tamanho do elemento [mm] & 20 & 15 & 10 & 8 & 7 & 6 & 5 & 4 & 3 \\
\hline Número de Elementos & 2.766 & 3.886 & 4.088 & 6.157 & 6.916 & 9.134 & 11.836 & 17.797 & 30.880 \\
\hline Tensão de Von Mises Máx [MPa] & 154.4 & 146.7 & 152.6 & 166.7 & 161.9 & 164.9 & 162.1 & 165.2 & 165.7 \\
\hline Fator de Segurança & 2.68 & 2.82 & 2.71 & 2.48 & 2.56 & 2.51 & 2.55 & 2.50 & 2.49 \\
\hline
\end{tabular}

Tabela 5.2: Convergência de Malha para o Cubo com flange de $4 \mathrm{~mm}$ de espessura

Com base nos resultados das Tabelas 5.1 e 5.2, fica evidenciado que o processo ainda não havia convergido em torno de um único valor. No entanto, foi necessário considerar os custos computacionais derivados das malhas mais refinadas. Estipulado pelo próprio software, otimizações decorrentes de malhas com elementos inferiores a $3 \mathrm{~mm}$ incorreriam em processos com duração superior a 48 horas. Considerando o número de otimizações a serem realizadas, estas malhas se tornaram inviáveis.

De acordo com os dados obtidos nas Tabelas 5.1 e 5.2, a malha com elementos de tamanho $3 \mathrm{~mm}$ apresenta uma diferença de tensão máxima resultante de $1,49 \%$ para o primeiro caso e $0.30 \%$ para o segundo caso. Esta análise permitiu definir o elemento de malha de $3 \mathrm{~mm}$ a ser utilizado nas otimizações visto que não apresenta erros significativos na solução. Para evidenciar a convergência encontrada, foi traçado um gráfico de dispersão para cada caso.

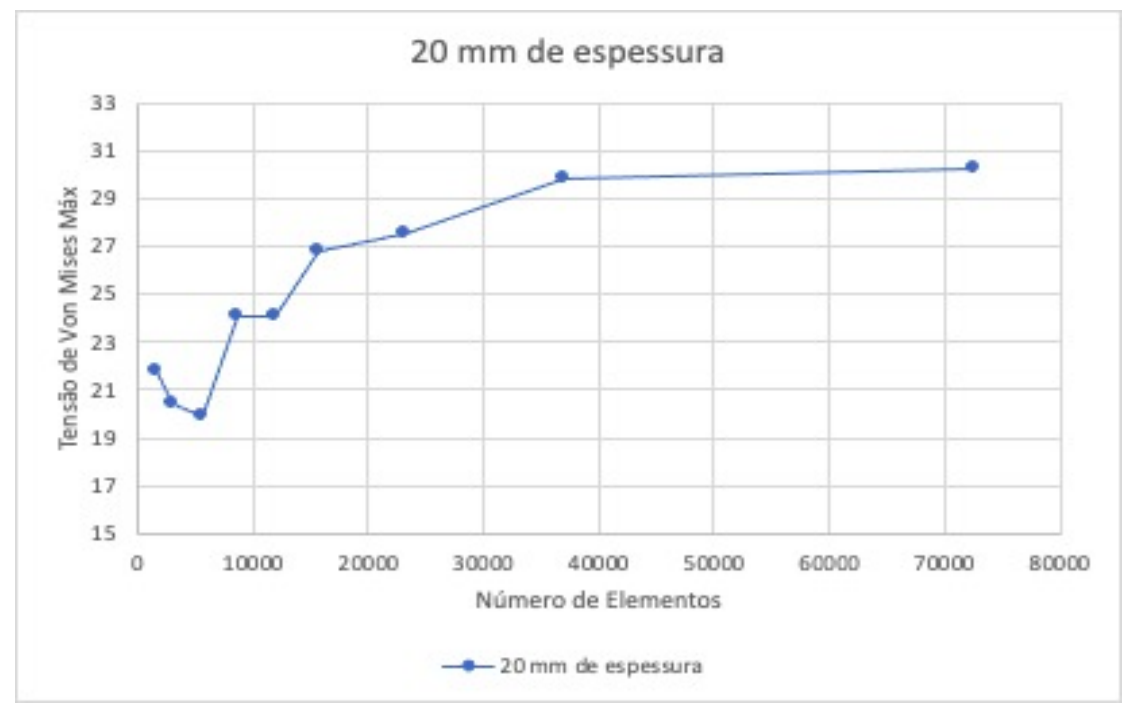

Figura 5.9: Gráfico Tensão Máxima X Número de Elementos de convergência de malha da flange com $20 \mathrm{~mm}$ de espessura 


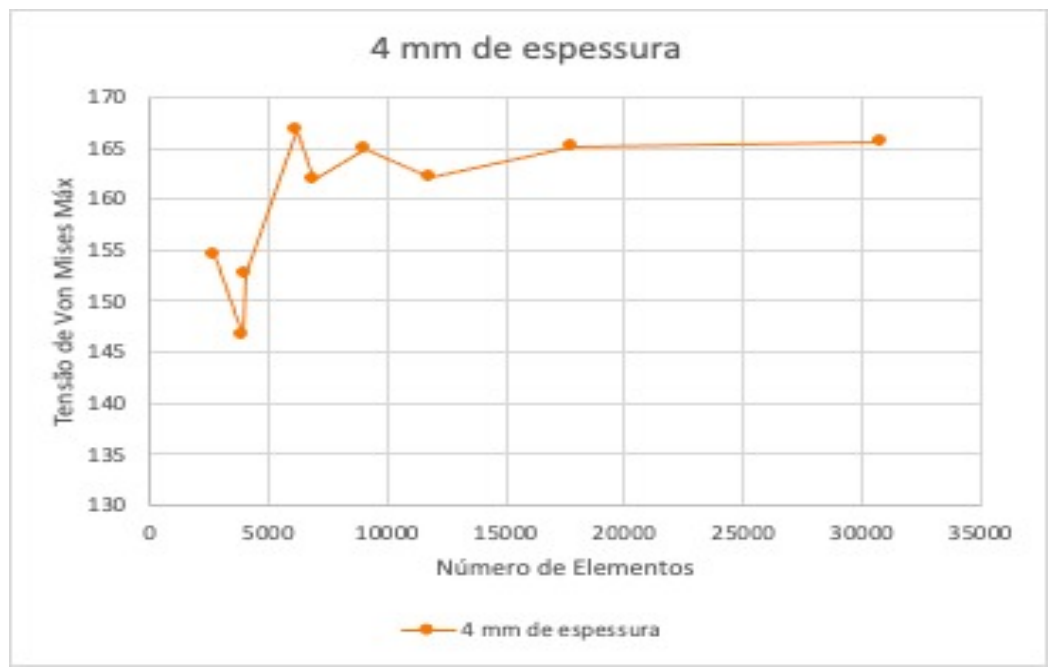

Figura 5.10: Gráfico Tensão Máxima X Número de Elementos de convergência de malha da flange com $4 \mathrm{~mm}$ de espessura

Visto que a malha gerada satisfaz a proposta do trabalho, foi iniciado o processo de simulação estrutural do componente com os parâmetros encontrados. 


\section{Resultados Obtidos}

Tendo em vista os forçamentos e condições de contorno implementados no software, presentes no Capítulo 4, e os parâmetros de simulação, apresentados no capitulo anterior, foi iniciado o processo de otimização estrutural do componente. Conforme descrito anteriormente, serão otimizadas 8 geometrias distintas a fim de comparar os resultados obtidos. Para isso, foram realizadas análises estáticas e, com base nos resultados, aplicada a ferramenta de otimização topológica do software. As Figuras 6.1 e 6.2 ilustram os resultados das análises estáticas para diferentes espessuras.
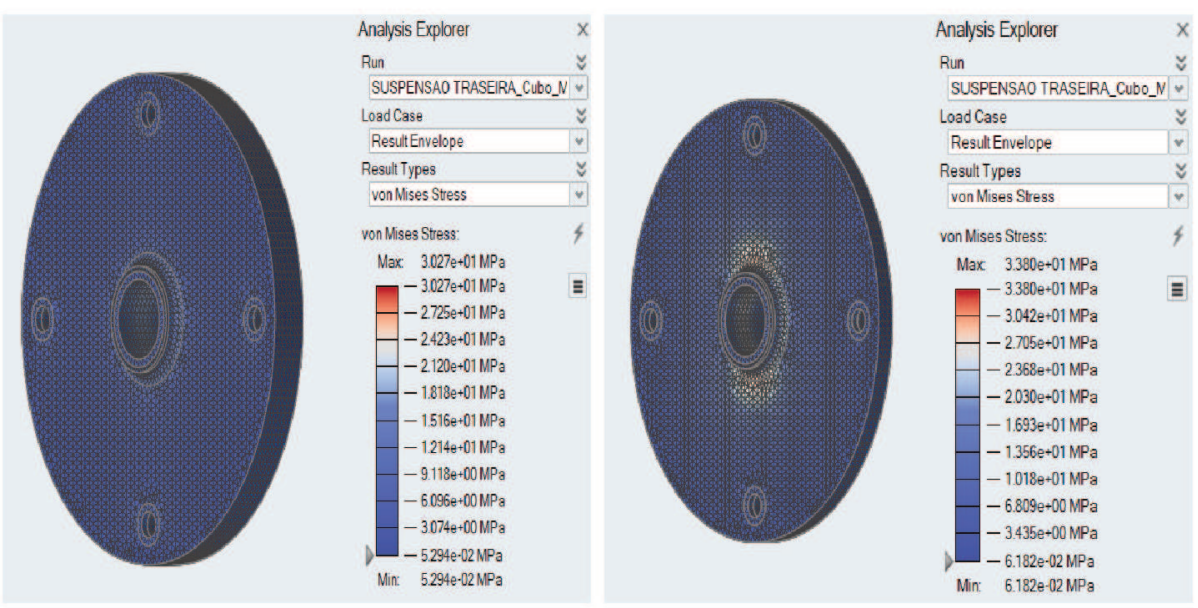

Figura 6.1: Análise estática das geometrias com flange de espessura $20 \mathrm{~mm}$ e $10 \mathrm{~mm}$, respectivamente
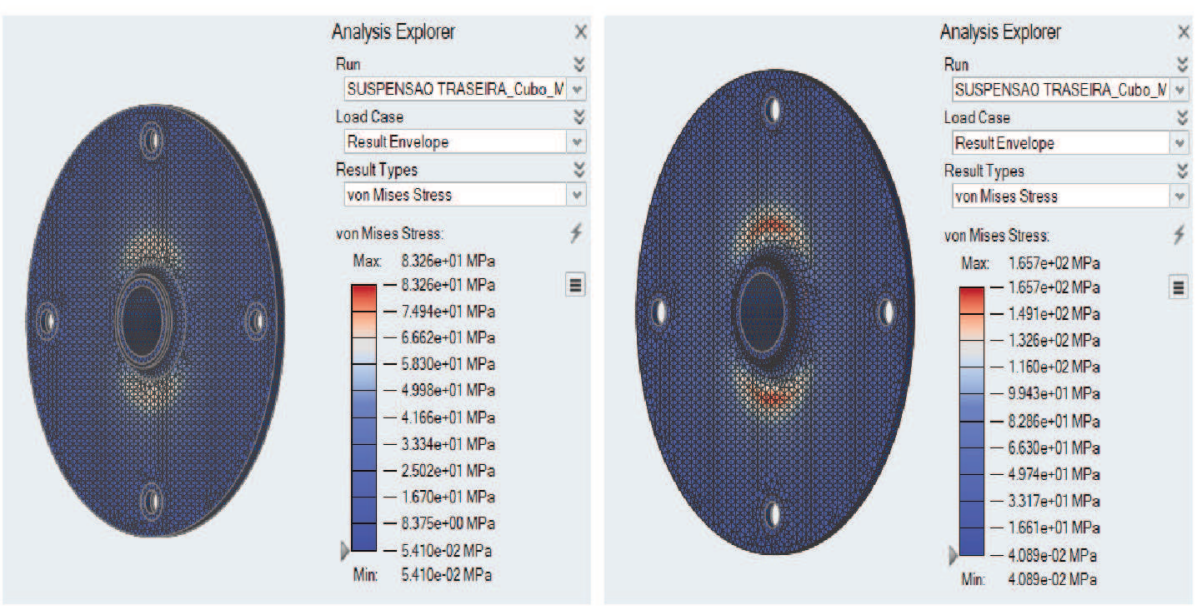

Figura 6.2: Análise estática das geometrias com flange de espessura 6 mm e 4 $\mathrm{mm}$, respectivamente 


\section{1}

\section{Otimização Topológica}

De posse das simulações estáticas das diferentes geometrias, foi iniciado o processo de otimização topológica do componente.

O software Altair Inspire possui um módulo interno de otimização topológica, podendo ser configurado com diferentes objetivos e restrições. Para o presente estudo, devido ao superdimensionamento do componente em sua geometria base, foi definido como objetivo da ferramenta de otimização a redução mássica do componente. Como restrição da simulação, foi adotada a manutênção do fator de segurança ao escoamento do mínimo 2, por meio da análise de tensões na peça durante sua otimização causada pelos casos de carga.

Os resultados das otimizações realizadas para todas as geometrias podem ser visualizados nas Figuras 6.3 a 6.6 :
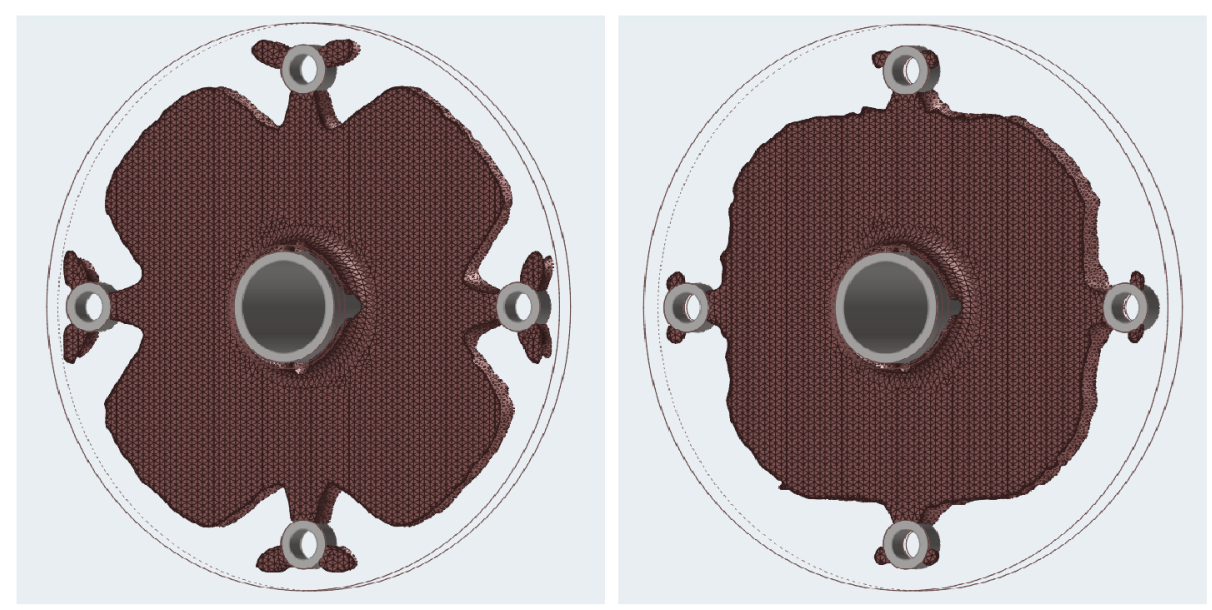

Figura 6.3: Otimização topológica das geometrias com flange de espessura 4 $\mathrm{mm}$ e $5 \mathrm{~mm}$, respectivamente 

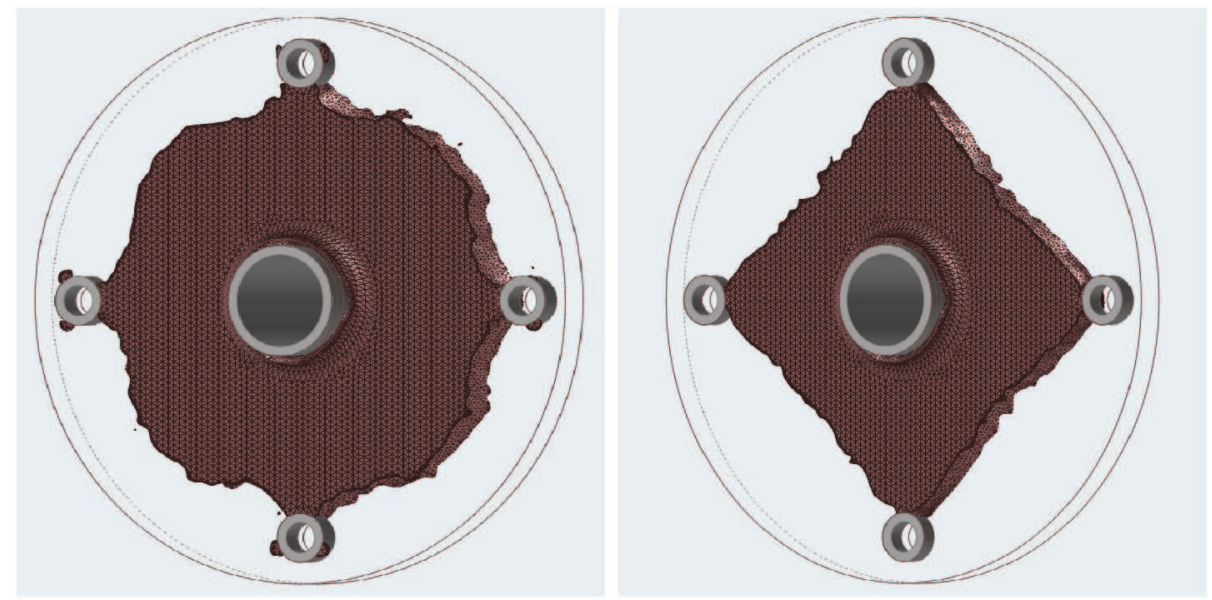

Figura 6.4: Otimização topológica das geometrias com flange de espessura 6 $\mathrm{mm}$ e $7 \mathrm{~mm}$, respectivamente
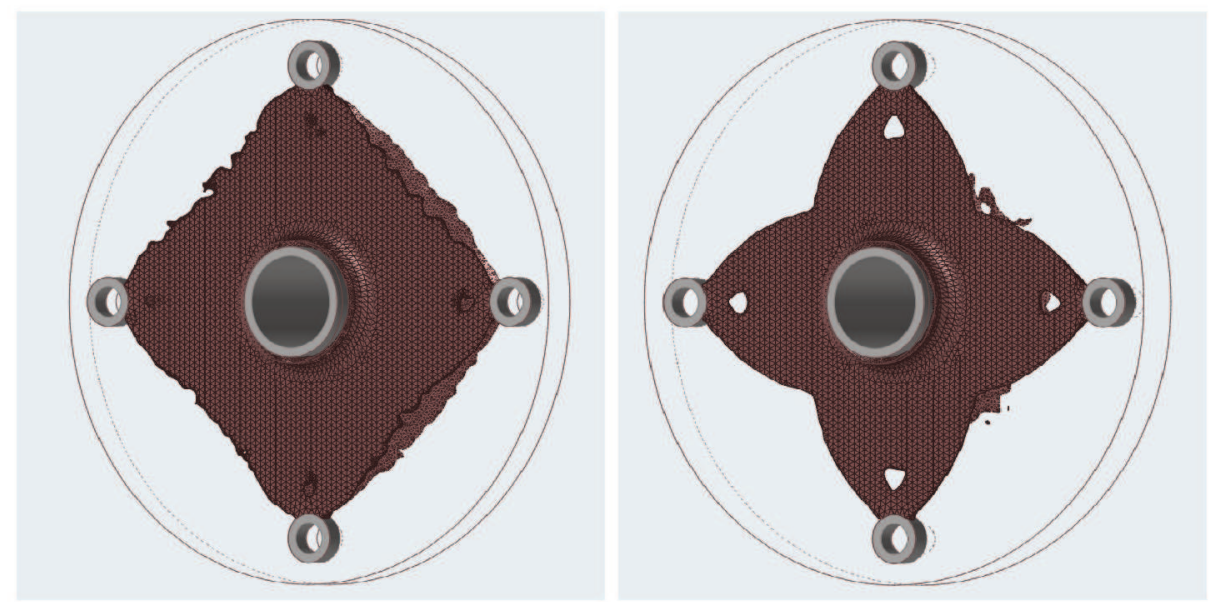

Figura 6.5: Otimização topológica das geometrias com flange de espessura 8 $\mathrm{mm}$ e $10 \mathrm{~mm}$, respectivamente 

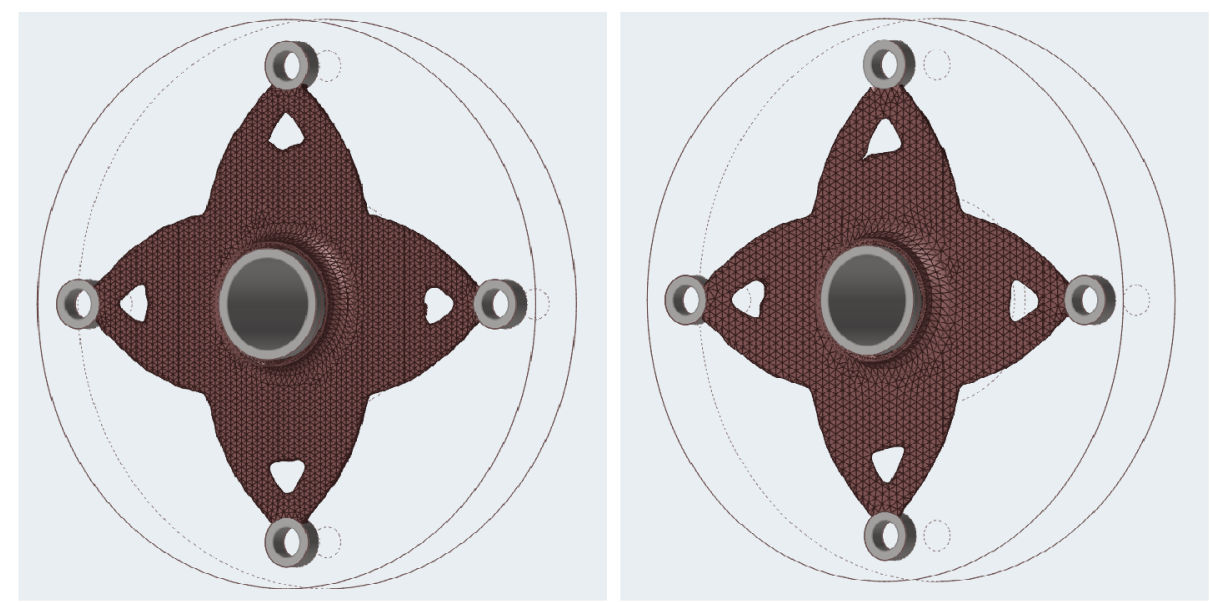

Figura 6.6: Otimização topológica das geometrias com flange de espessura 15 $\mathrm{mm}$ e $20 \mathrm{~mm}$, respectivamente

Como é possível observar, há uma notória diferença entre as geometrias resultantes, considerando não somente sua disposição física de material mas da massa resultante do componente. A Tabela 6.1 e a Figura 6.7 apresentam as massas iniciais (pré-otimização) e ótimas após o processo de otimização, evidenciando o melhor resultado encontrado como a otimização do cubo com flange de $20 \mathrm{~mm}$ de espessura.

Espessura da Flange Massa Original Massa Resultante

\begin{tabular}{cll}
\hline $4 \mathrm{~mm}$ & $359 \mathrm{~g}$ & $217 \mathrm{~g}$ \\
\hline $5 \mathrm{~mm}$ & $429 \mathrm{~g}$ & $210 \mathrm{~g}$ \\
\hline $6 \mathrm{~mm}$ & $499 \mathrm{~g}$ & $197 \mathrm{~g}$ \\
\hline $7 \mathrm{~mm}$ & $569 \mathrm{~g}$ & $152 \mathrm{~g}$ \\
\hline $8 \mathrm{~mm}$ & $639 \mathrm{~g}$ & $133 \mathrm{~g}$ \\
\hline $10 \mathrm{~mm}$ & $779 \mathrm{~g}$ & $121 \mathrm{~g}$ \\
\hline $15 \mathrm{~mm}$ & $1130 \mathrm{~g}$ & $106 \mathrm{~g}$ \\
\hline $20 \mathrm{~mm}$ & $1476 \mathrm{~g}$ & $109 \mathrm{~g}$ \\
\hline
\end{tabular}

Tabela 6.1: Redução mássica das diferentes geometrias após o processo de otimização 


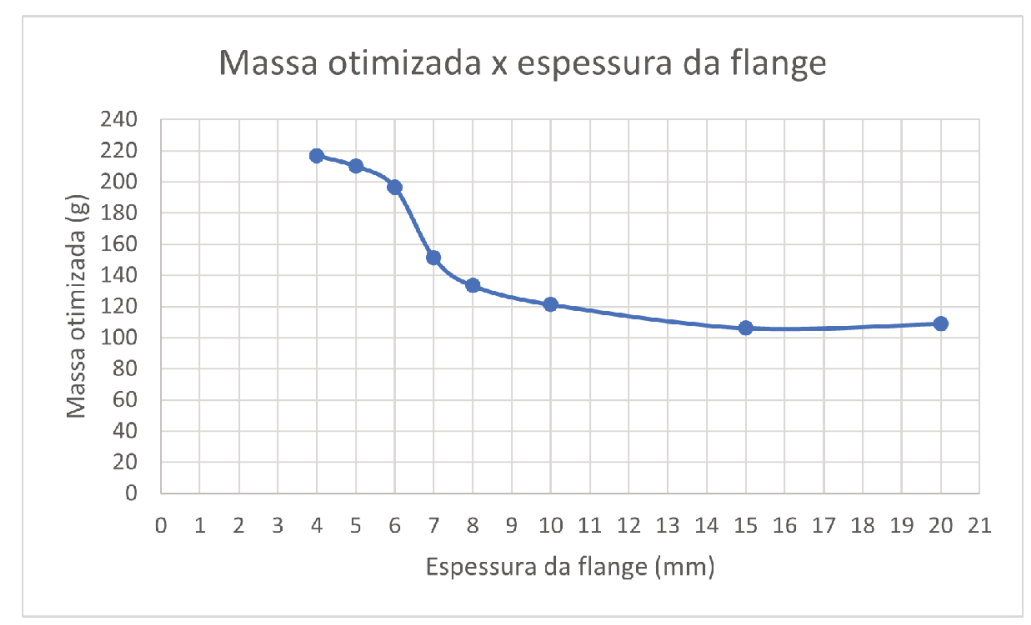

Figura 6.7: Variação da massa otimizada em função da espessura da flange do cubo de roda

Este resultado pode ser explicado pela utilização de uma geometria mais básica possível, permitindo que o software realizasse a remoção do material sem interferência do projetista. Além disso, o aumento do volume do sólido, para uma mesma malha, permite a utilização de um maior número de nós e elementos na simulação. Este aumento afeta positivamente as simulações numéricas realizadas pelo software durante o processo de otimização.

\section{2}

\section{Geometria Final}

A partir dos resultados obtidos, foi necessário escolher a melhor geometria para iniciar o processo de pós-processamento da peça, ou seja, a suavização da topologia gerada. Apesar do cubo de roda com $15 \mathrm{~mm}$ de espessura de flange ter apresentado a menor massa final, sua topologia apresentou áreas com material desconexo do corpo, portanto, optou-se pela geometria resultante da otimização do cubo de roda com flange de $20 \mathrm{~mm}$ de espessura. Com base em suas dimensões e adicionando filetes no corpo para evitar concentração de tensões em "cantos vivos", a nova geometria foi modelada considerando que sua fabricação fosse possível utilizando um torno mecânico e uma fresadora, máquinarios simples e presentes na própria PUC, facilitando sua manufatura pela Equipe Reptiles. As Figuras 6.8 e 6.9 apresentam a topologia ótima e a geometria final. 

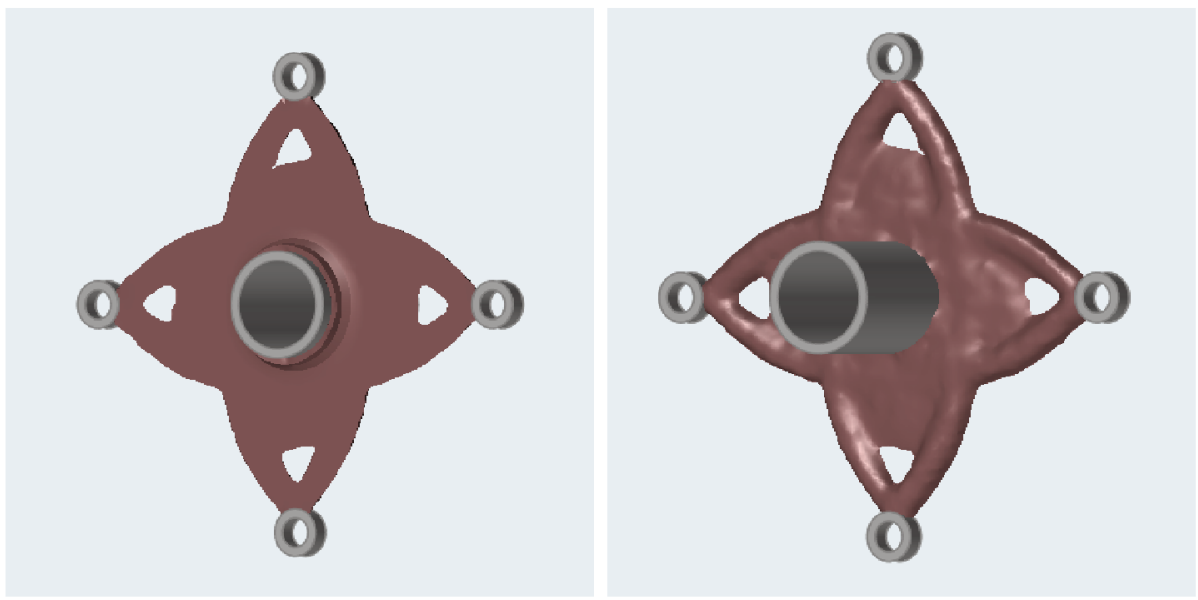

Figura 6.8: Otimização topológica das geometrias com flange de espessura 20 $\mathrm{mm}$
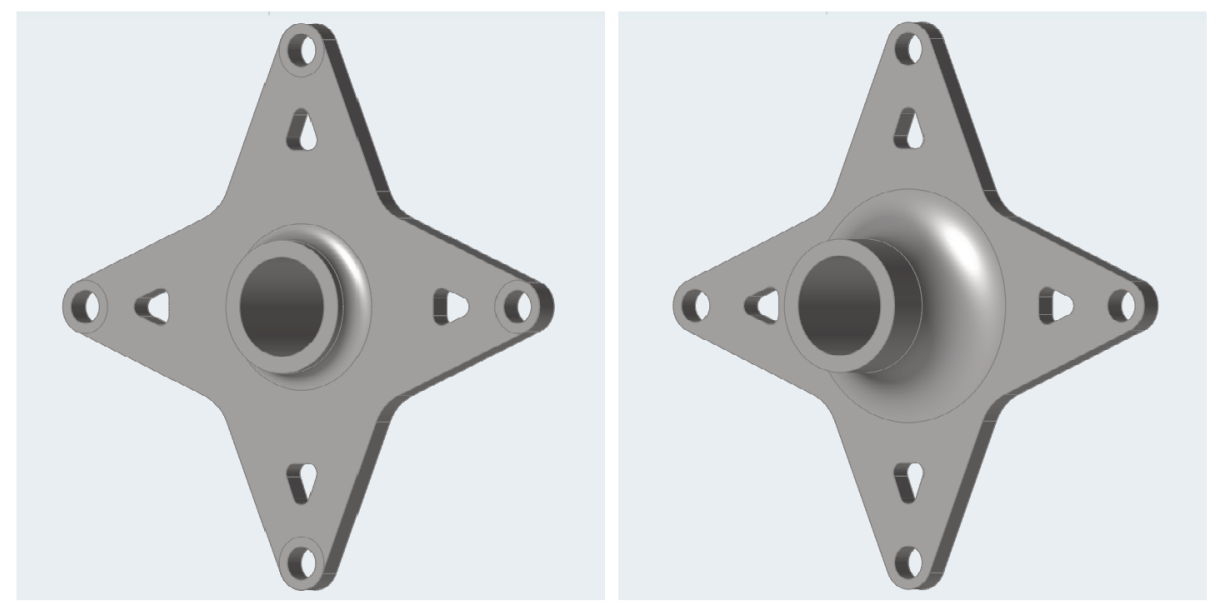

Figura 6.9: Geometria otimizada do Cubo de Roda Traseiro

Por fim, o último passo consistiu na validação da geometria resultante submetendo a mesma aos casos de carga apresentados durante este trabalho. Novamente foi realizada a análise estática do componente com a malha gerada no Capitulo 5. O resultado da nova simulação pode ser visualizado na Figura 6.10. 


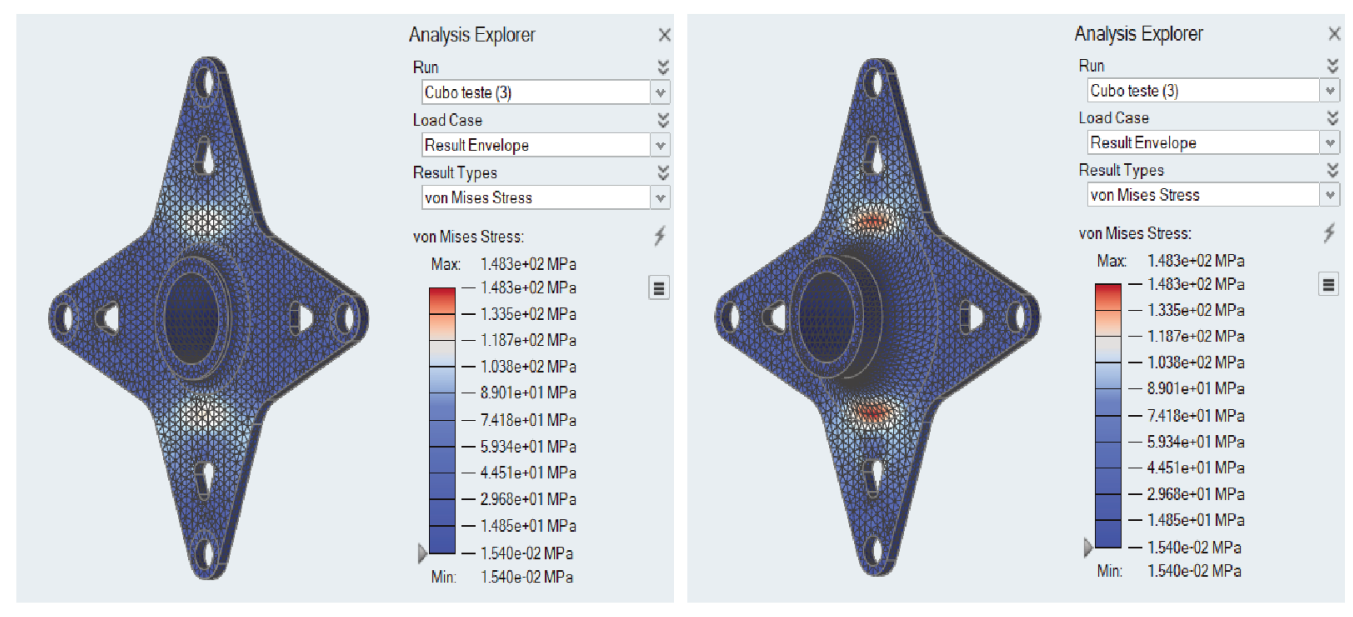

Figura 6.10: Análise estrutural do componente otimizado

Com base nos resultados obtidos na simulação, podemos finalmente analisar comparativamente (ver Tabela 6.2) a massa dos componentes estudados e seus fatores de segurança contra o escoamento, foco do presente trabalho.

\begin{tabular}{cccc} 
Parâmetro & Cubo Original & Cubo Otimizado & Variação \\
\hline Massa & 6.0 & 2.8 & $-53.3 \%$ \\
\hline
\end{tabular}

Tabela 6.2: Comparativo dos resultados obtidos 


\section{7 \\ Conclusões}

Os resultados demonstrados ao longo dos capítulos anteriores, culminando na geometria final projetada, permitiram alcançar a otimização do componente sem abrir mão de sua segurança estrutural. A continuação deste tipo de trabalho é crítica para a evolução da equipe dentro das competições da modalidade, visando sempre a relação desempenho e segurança das peças do veículo.

É importante ressaltar que o trabalho pode, e deve ser continuado, levando em consideração o dimensionamento à fadiga do componente. Apesar da vida curta da peça, tendo que ser renovada a cada 2 anos por exigência do regulamento, sua validação deve ser realizada para plena confiabilidade de uso. Outra possibilidade de otimização pode ser realizada por meio do estudo do material do componente, avaliando a utilização de materiais plásticos ou poliméricos, cada vez mais presente na indústria automotiva. Por fim, apesar da dificuldade devido à dinâmica da peça, a obtenção dos esforços reais no componente por instrumentação durante sua utilização permitirá realizar de forma mais precisa possível sua análise estrutural.

Consideramos, portanto, que o principal objetivo deste trabalho, que foi apresentar possíveis técnicas simplificadas de obtenção de esforços para dimensionamento dos componentes de forma segura e demonstrar as diferenças de processos de otimização partindo desde uma peça já otimizada para uma peça "virgem", obtendo diferentes resultados, foi atingido de forma satisfatória. 


\section{Referências Bibliográficas}

[1] FREITAS, L. M. P. Estudo da dinâmica vertical de uma suspensão veícular do tipo macpherson. Dissertação de mestrado, Escola de Engenharia de São Carlos, Universidade de São Paulo, São Carlos, 2006.

[2] MILLIKEN, W. F.; MILLIKEN, D. L. Race Car Vehicle Dynamics. SAE International, Pennsylvania, 2nd edition, 1995.

[3] SAE Brasil. Regulamento administrativo e técnico Baja SAE Brasil, 2019.

[4] MATILDE, L. H. Análise de tensões e otimização topológica do cubo de roda de um veiculo Off Road baja sae. Projeto de graduação, Departamento de Engenharia Mecânica, Pontifícia Universidade Católica do Rio de Janeiro, Rio de Janeiro, 2019.

[5] ROERHRS, R. C. K. Projeto e desenvolvimento de uma caixa redutora para um veiculo fora-de-estrada. Projeto de graduação, Departamento de Engenharia Mecânica, Pontifícia Universidade Católica do Rio de Janeiro, Rio de Janeiro, 2018.

[6] NOVIS, P. H. S. Otimização topológica e estimativa de vida à fadiga da manga de eixo traseira de um veículo off road baja sae. Projeto de graduação, Departamento de Engenharia Mecânica, Pontifícia Universidade Católica do Rio de Janeiro, Rio de Janeiro, 2020.

[7] LIMA, D. S. S. Projeto de cubo de roda e manga de eixo para protótipo de fórmula sae. Projeto de graduação, Departamento de Engenharia Mecânica, Universidade Federal Fluminense, Niterói, 2016.

[8] AMORIM, A. E.; ALVES W. S. Estudo de viabilidade de execução de teste simulando o comportamento do protótipo baja em estado estacionário em uma trajetória curvilínea. Projeto de graduação, Universidade Federal do Espírito Santo, Vitória, 2013.

[9] BASTOS, T. S. Projeto e desenvolvimento do sistema propulsor de um veículo recreativo do tipo "fora-de-estrada", 2016. 
A

Código MATLAB para as contas executadas

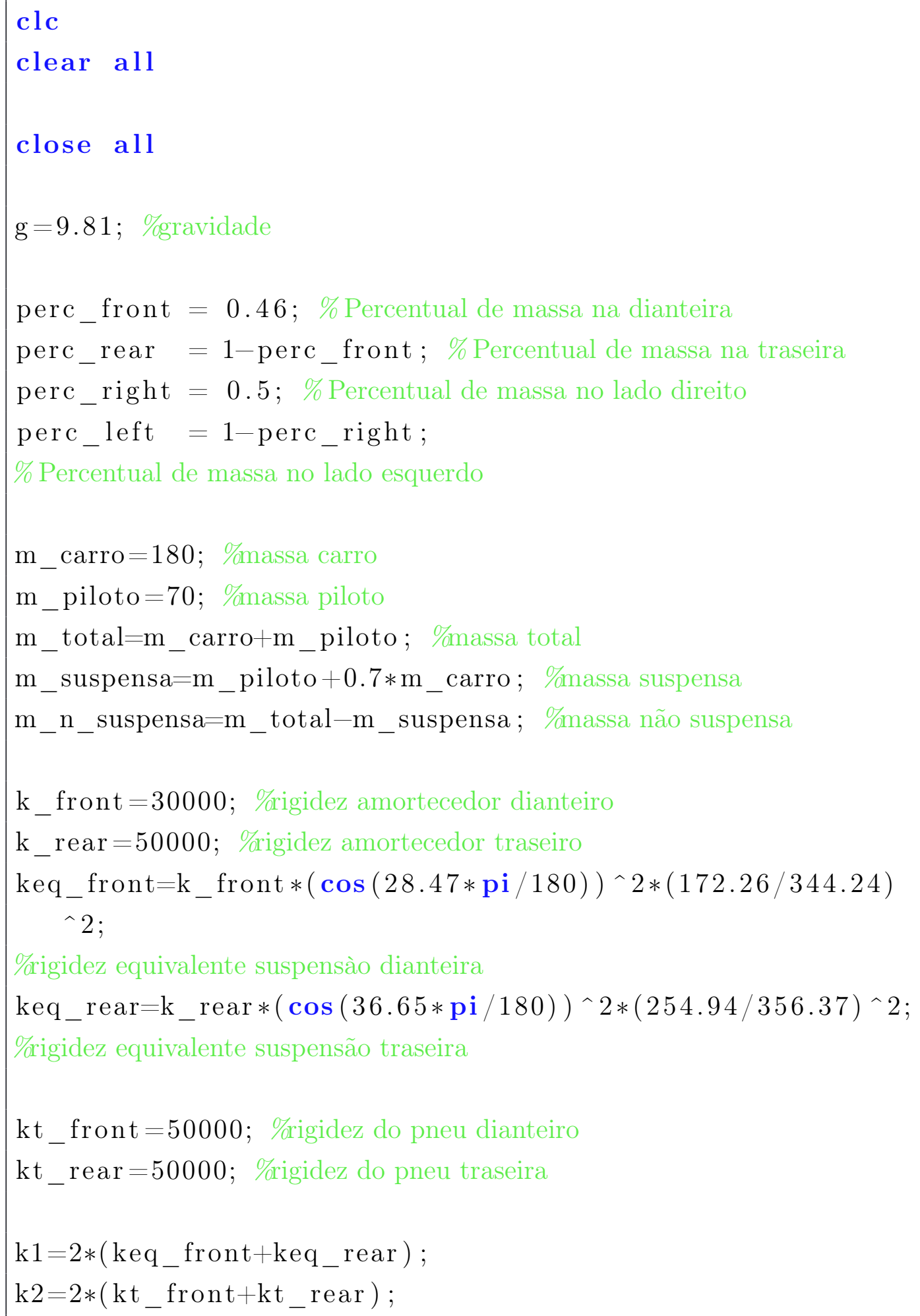




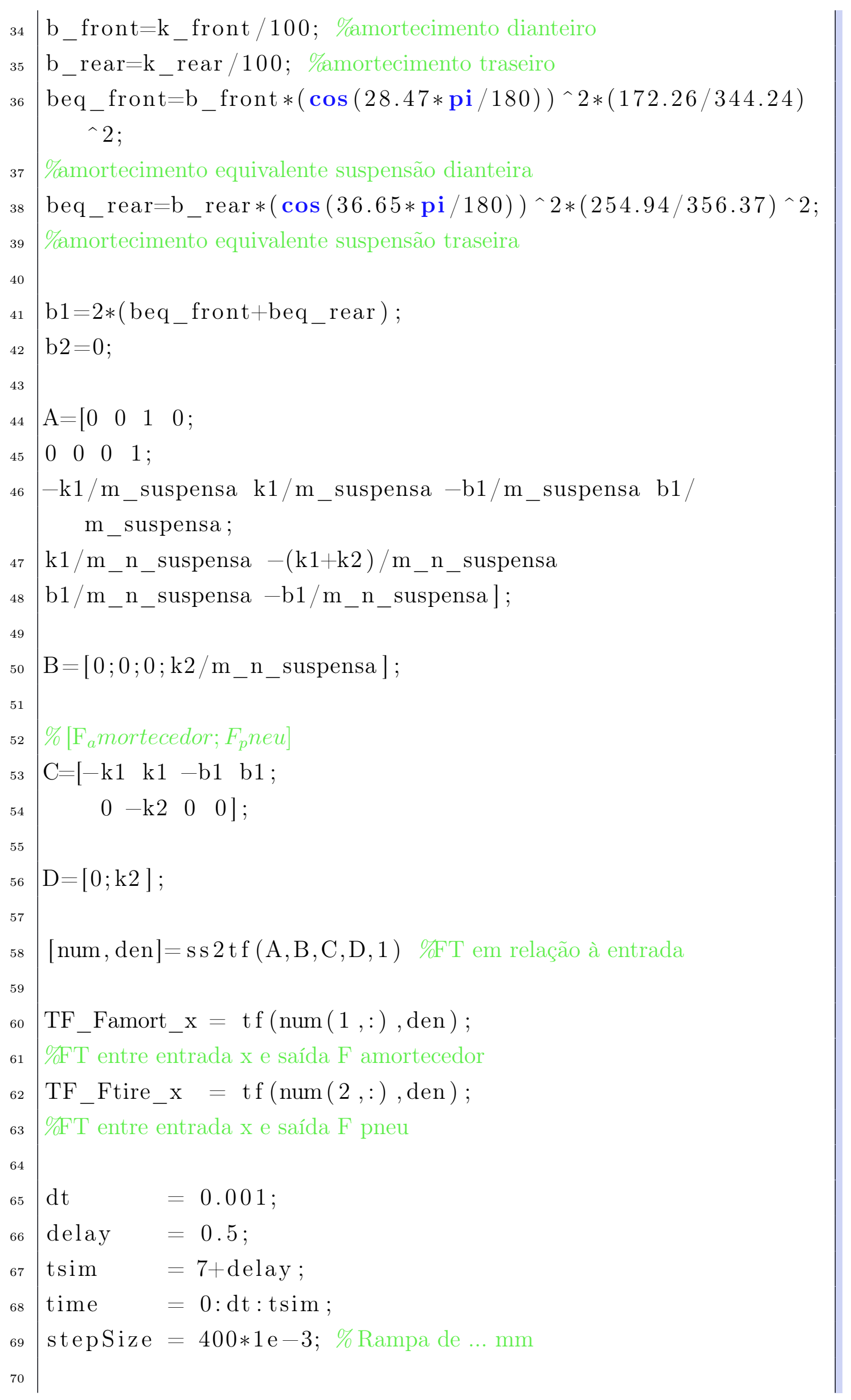




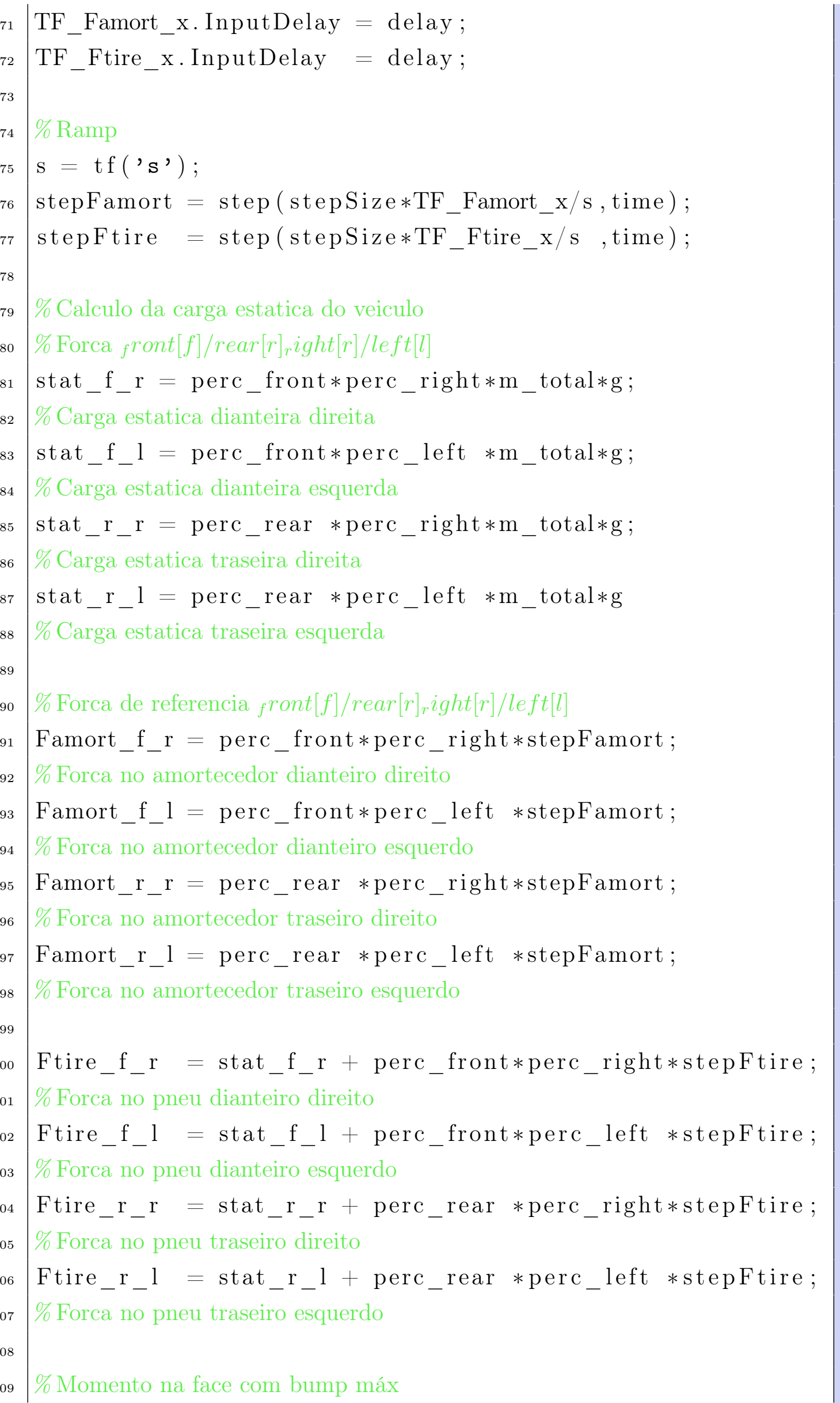




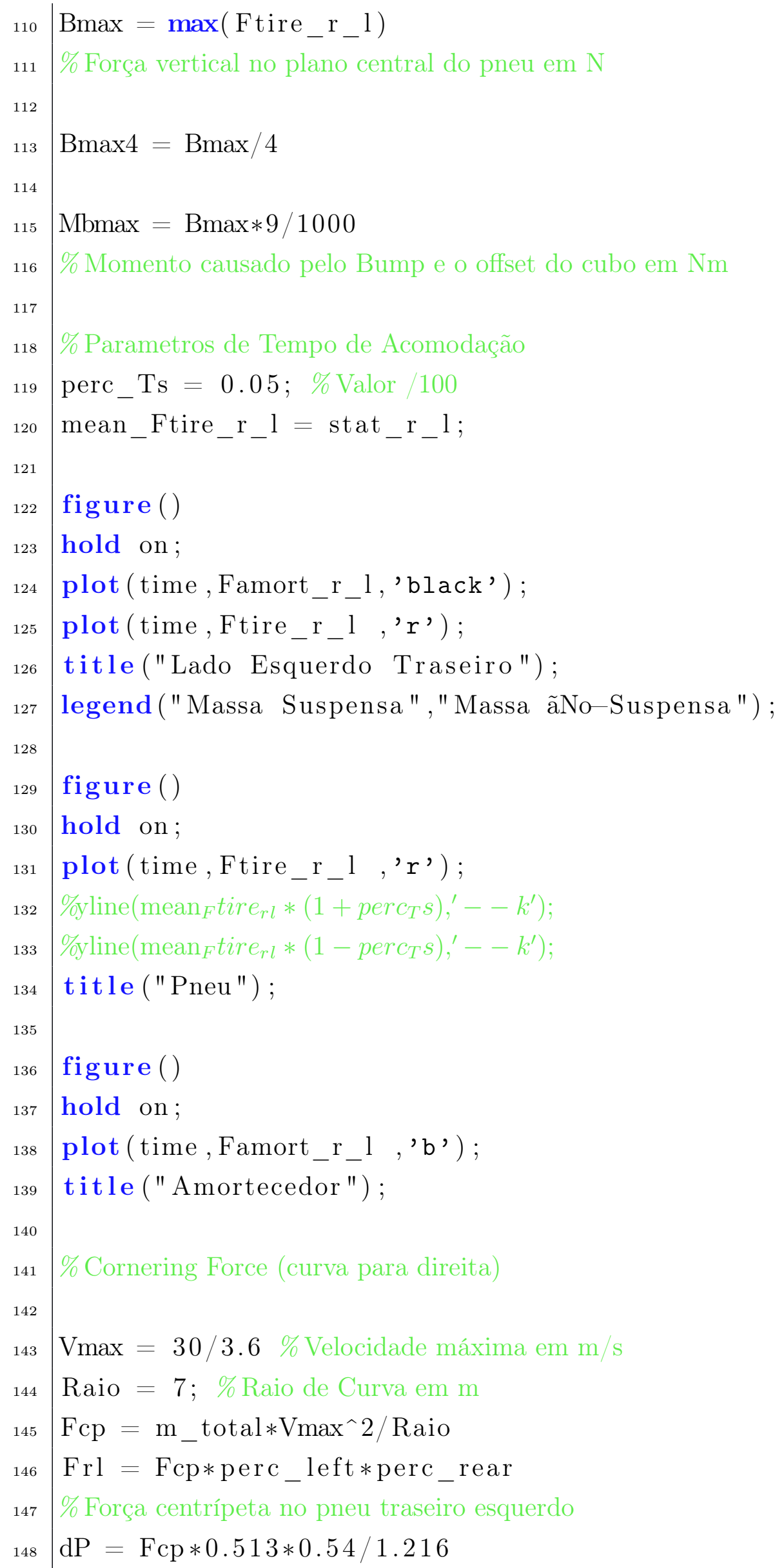




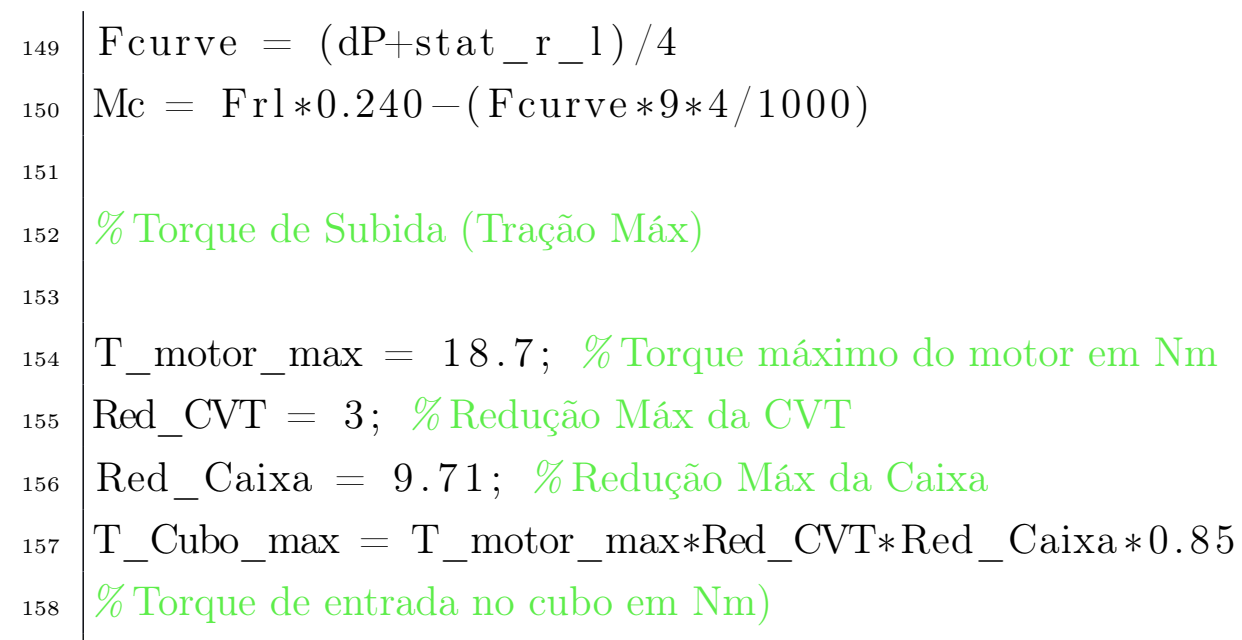

